\title{
Late winter temperature response to large tropical volcanic eruptions in temperate western North America: Relationship to ENSO phases
}

\author{
Eugene R. Wahl ${ }^{\text {a, } *}$, Henry F. Diaz ${ }^{\text {b }}$, Jason E. Smerdon ${ }^{c}$, Caspar M. Ammann ${ }^{\text {d }}$ \\ a National Oceanic and Atmospheric Administration, National Climatic Data Center, Paleoclimatology Branch, 325 Broadway, CO 80305, USA \\ ${ }^{\mathrm{b}}$ National Oceanic and Atmospheric Administration, Cooperative Institute for Research in Environmental Sciences, University of Colorado, 325 Broadway, CO 80305, USA \\ ${ }^{c}$ Lamont-Doherty Earth Observatory of Columbia University, 61 Route 9W, Palisades, NY 10964, USA \\ d National Center for Atmospheric Research, Research Applications Laboratory, 3450 Mitchell Lane, Boulder, CO 80301, USA
}

\section{A R T I C L E I N F O}

\section{Article history:}

Received 18 November 2013

Received in revised form 1 August 2014

Accepted 8 August 2014

Available online 23 August 2014

\section{Keywords:}

El Niño

La Niña

volcanoes

climate forcing

post-volcanic response

paleoclimatology

\begin{abstract}
A B S T R A C T
February-March temperature reconstructions in western North America from 1500-1980 in the Common Era (CE) are used to evaluate, from a regional perspective, the hypothesis that radiative forcing by large tropical volcanic eruptions induces a tendency in the climate system towards an early post-event El Niño (EN) response followed by a delayed La Niña (LN) response. Post-event spatial composites using superposed epoch analysis (SEA) detect indications for an EN-like pattern in post-event Years 1-2; this result, however, is sensitive to the set of eruptions evaluated. Highly significant LN-like patterns are also observed for two eruptions during Year 1. In contrast, a clear and unique LN-like response is found in both evaluated eruption sets during Years 3-5; Year 3 in particular represents the time of strongest post-event response. No significant EN-like patterns occur during these years. The relative homogeneity of the SEA response for each post-event year is evaluated in terms of the ratio of the amplitude of the SEA composite to its standard deviation across the eruption events. In relation to the same metric determined from random-event-year SEAs, these signal-to-noise ratios are most highly significant in the portions of the domain with the strongest anomalies in Years 1-5, especially Year 3 . The signal-to-noise ratios tend towards uniformly low and insignificant values beyond the first half-decade after the eruption, indicating generally reduced coherence across events. In relation to the larger-scale circulation, post-eruption 500mb February-March geopotential height composites from the 20th Century Reanalysis show ENSO-type features that are largely consistent with the SEA results from the primary eruption set during Year 1 , but are inconsistent with the EN-like pattern exhibited by the second eruption set during Years 1-2. In Year 3, the pressure composite over North America and the adjacent Pacific and Atlantic is strongly LN-like, consistent with all SEA results; similarly, weakening coherence across events as time progresses beyond Year 3 is also consistent with more variable pressure composites noted after that time. The relatively robust character of the delayed LN-like response is evaluated in terms of the dynamic rebound of the climate system towards its initial energy balance as the radiative impact of immediate post-eruption aerosol cooling dissipates. The LN-like SEA temperature response in Years 3-5 exhibits a slight shift of its southern warm anomaly to the north and west relative to pure composite LN conditions, which is detected as a specifically post-eruption feature in the region.
\end{abstract}

Published by Elsevier B.V.

\section{Introduction}

In light of anthropogenic forcing from increases in greenhouse gas concentrations, significant evaluation of the response of the climate system to a range of forcing factors has been undertaken (Myhre et al., 2013), with the goal of better understanding the system's sensitivities to exogenous radiative forcing factors. Responses to large tropical volcanic eruptions, which have the capacity to affect both hemispheres, are a

\footnotetext{
* Corresponding author. Tel.: +1 3034976297.

E-mail addresses: Eugene.R.Wahl@noaa.gov (E.R.Wahl), Henry.F.Diaz@noaa.gov (H.F. Diaz), jsmerdon@ldeo.columbia.edu (J.E. Smerdon), ammann@ucar.edu (C.M. Ammann).
}

key area of focus in this regard, and provided an early validation of climate models after the Pinatubo event (Hansen et al., 1992). This interest arises in part because dynamical responses occur in conjunction with the direct radiative balance effects and can outlast them for periods of several years (Driscoll et al., 2012; Myhre et al., 2013), and such responses have specific regional "fingerprints" (e.g., Fischer et al., 2007; Ammann et al., 2010; Anchukaitis et al., 2010; Driscoll et al., 2012) and effects on teleconnection source regions, such as the equatorial Pacific and the El Niño/Southern Oscillation (ENSO) system (Adams et al., 2003; Mann et al., 2005; Emile-Geay et al., 2008; D'Arrigo et al., 2009; Wilson et al., 2010; Li et al., 2013). High-resolution paleoclimatology offers the only observational means to extend the study of these responses beyond the instrumental data period, providing several 
times more eruption events to be evaluated including particularly large eruptions such as Tambora (1815), and thereby facilitating a more robust evaluation of the coherence or spread of responses across events. In particular, annually- to seasonally-resolved reconstructions of climate, coupled with good volcanic chronologies and evaluations of forcing efficacy from multiple ice cores and independent geological eruption evidence, offer the chance to study the temporal evolution of the dynamical responses (e.g., Adams et al., 2003; Mann et al., 2005; Emile-Geay et al., 2008; D'Arrigo et al., 2009; Anchukaitis et al., 2010; Wilson et al., 2010; Li et al., 2013) and can take advantage of the existence of climate proxy data richness in some parts of the world to allow regional responses to be evaluated (Fischer et al., 2007; Anchukaitis et al., 2010; cf. Landrum et al., 2013).

In this work, we expand on limited initial results reported in Landrum et al. (2013) (cf. Fig. 10 and associated text there) and present a detailed analysis of late winter (February-March, or FM) post-volcanic temperature responses in temperate western North America over the past 500 years. This spatially-explicit regional North American analysis takes advantage of region-specific potential for successful spatial reconstruction due to the richness of annually-resolved proxy data in western temperate North America, an approach supported by "pseudoproxy" simulation experiments that have demonstrated that regional climate field reconstruction skill improves with increased proxy density in heterogeneous proxy networks (Smerdon et al., 2011). Similar to
Anchukaitis et al. (2010), who use a spatially-explicit reconstruction of hydroclimate variability in Asia to evaluate the dynamical hypothesis that large volcanic eruptions should result in anomalous dry conditions in the monsoon portions of the region, or Wegmann et al. (2014) who analyze a spatially-explicit reconstruction of post-volcanic precipitation over Europe, we take advantage of the regional western North American dynamic connection to ENSO activity (Fig. 1) to focus specifically on evaluating the hypothesis that large tropical eruptions are associated with a probabilistic tendency towards an early El Niño (EN) like response followed by a delayed La Niña (LN) like response. This hypothesis is supported by a number of paleoclimate and model study results and has been the subject of significant evaluation in the last-millennium paleoclimate literature over the past decade or more (cf. Adams et al., 2003; Mann et al., 2005; Emile-Geay et al., 2008; D'Arrigo et al., 2009; Wilson et al., 2010; Li et al., 2013). The spatial "fingerprinting" that our analysis allows is particularly important in this context: first, because strong, interannual spatial dipole behavior in western North America is distinctly associated with ENSO activity (Fig. 1) and thus across-region averages could be significantly dampened in terms of their amplitude of response; and second, because relatively subtle differences in spatial patterns (at the continental scale) can potentially carry significant information about ENSO-related and non-ENSO-related responses (cf. Summary and discussion, Section 4.4).
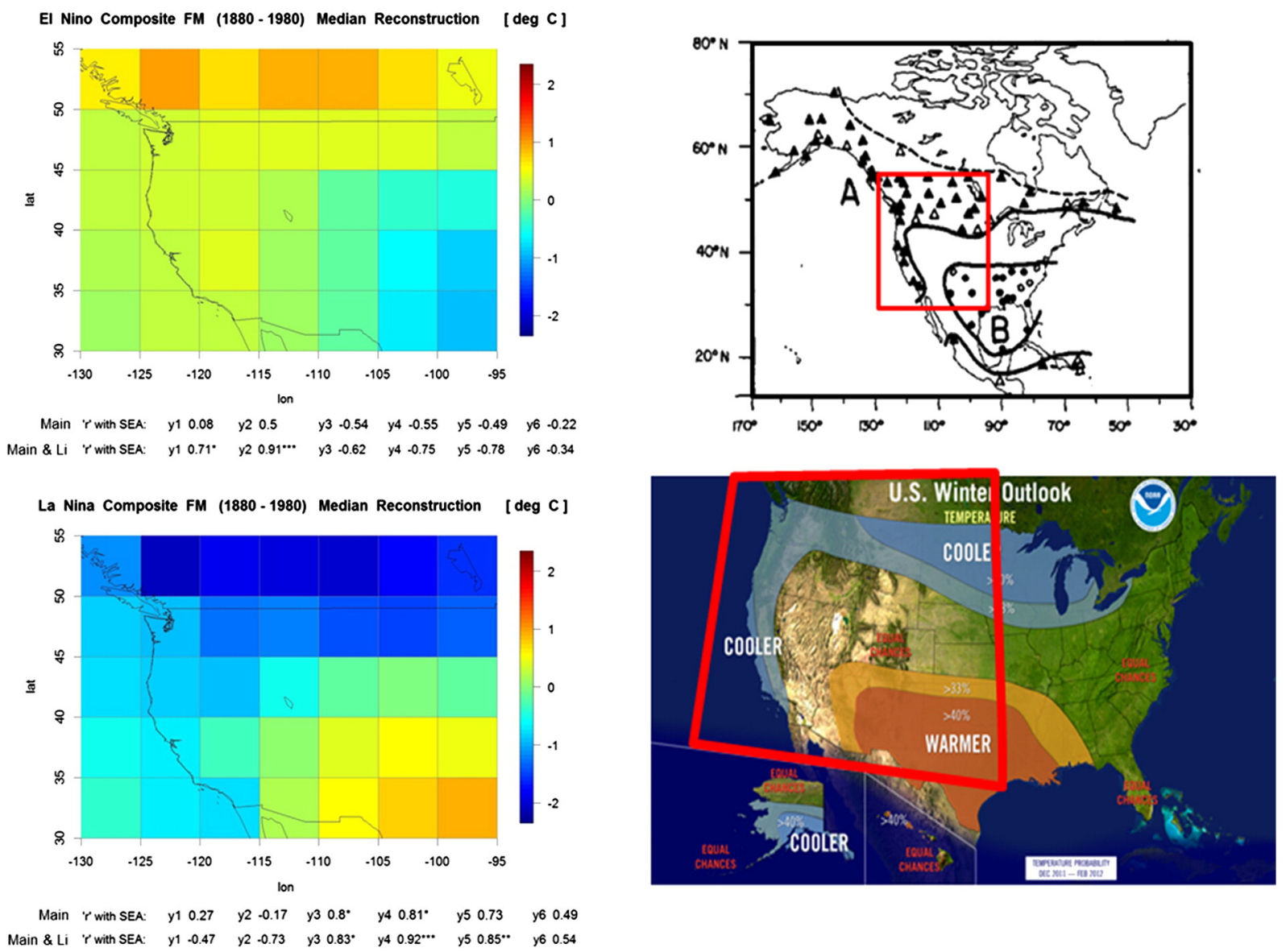

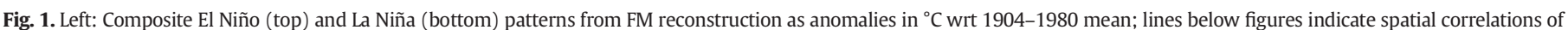

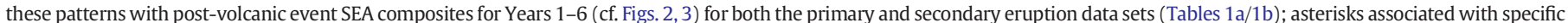

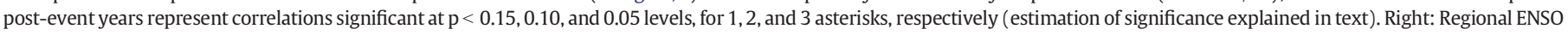

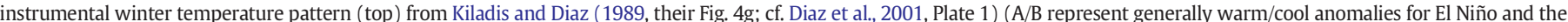

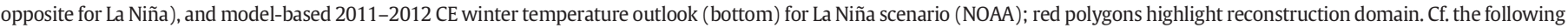

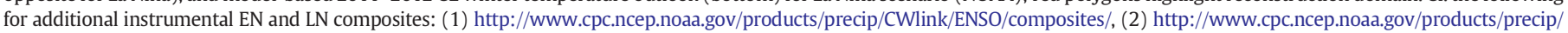
CWlink/ENSO/composites/EC_LNT_index.shtml. (For interpretation of the references to color in this figure legend, the reader is referred to the web version of this article.) 
The western North American FM temperature reconstructions carry information regarding the dynamical regional response to ENSO behavior that is independent of direct reconstructions of tropical Pacific sea surface temperatures (SSTs), and thus can serve to independently test the "early EN/delayed LN" hypothesis. Dynamic considerations based on the Bjerknes feedback (cf. Clement et al., 1996) have been used to explain the post-volcanic variations in reconstructed SSTs in the tropical Pacific (cf. Adams et al., 2003; Mann et al., 2005; Emile-Geay et al., 2008). This mechanism works through the effect of reduced surface insolation that weakens the primary convection in the western Pacific warm pool area, leading to reduced trade wind strength and thus the potential for initiation of sub-surface Kelvin waves from west to east, and in turn EN warming at the surface in the eastern tropical Pacific. This process has been proposed to "reset" the internal variability "clock" of the ENSO climate system (Adams et al., 2003). One hypothesis for a delayed LN is then simply the rebound from the initial EN response, which would be expected to become increasingly less systematically expressed as time progresses from the initial induced EN (Adams et al., 2003; Mann et al., 2005; Emile-Geay et al., 2008). Yet, if the radiative forcing imposed by the eruption is responsible for the initial (EN-like) dynamical response, then the same physical explanation should also apply to the response of the tropical Pacific to the renewed convective activity after the radiative cooling perturbation from the eruption has decayed. Strengthened convection would reinforce the trade wind system that pushes warm tropical waters westward, inducing enhanced upwelling and thus LN-like conditions in the eastern tropical Pacific. This response would be expected to occur with return to the pre-eruption energy balance, and thus a delayed LN-like pattern would not be necessarily tied to the existence of an initially-induced EN, as previously suggested (Adams et al., 2003; Mann et al., 2005; Emile-Geay et al., 2008; cf. Li et al., 2013). We evaluate these dynamical considerations using the new western North American record.

The late winter/early spring seasonality in our study arises from a combination of two factors: first, the ENSO response in western North America is typically at its strongest in the winter and spring following the onset of EN or LN conditions (cf. Kiladis and Diaz, 1989); and second, FM is the only version of a tree ring-based sub-annual temperature reconstruction in the target region that demonstrated both successful calibration and validation performance (cf. Data and methods for further information). Although December-February or January-March periods might presumably be preferred for a "winter" response in this regard, the regional FM temperature reconstructions exhibit a clear spatial EN and LN signal during the instrumental period that closely conforms to known ENSO winter temperature patterns (Fig. 1); thus, there is demonstrated capacity to use the FM reconstructions for regional evaluation of the hypotheses mentioned regarding ENSO-related post-volcanic responses.

It should be noted that we do not evaluate the extent to which an immediate LN-like response potentially occurs in the first few months after the eruption itself (McGregor and Timmermann, 2011; Li et al., 2013) as fully as the analyses we present for the years afterwards, which is a necessary result of the timing of the FM reconstruction season early within the calendar year and the lag of atmospheric circulation response to ENSO-region SSTs (cf. Kiladis and Diaz, 1989). A brief evaluation of regional composite temperature patterns for the eruptionyear is provided in the Supplemental material, Section IV.

\section{Data and methods}

The proxies employed are tree ring widths and ring density data from the target reconstruction region $\left(30-55^{\circ} \mathrm{N}, 95-130^{\circ} \mathrm{W}\right)$ and northern Mexico that are calibrated (1904-1980 CE) and validated (1875$1903 \mathrm{CE}$ ) using $5 \times 5^{\circ}$ gridded instrumental surface temperature data. Details concerning the proxy and instrumental target data sets including the spatial locations of the proxy data are provided in Sections II and III of the supplemental material of Wahl and Smerdon (2012; hereafter "WS12"), and additional information is included in Section I of the supplemental material of this article. The truncated EOFprincipal components spatial regression (TEOF-PCSR) method, optimization procedures and a variety of methodological evaluations are described in WS12 and its supplemental material (Sections I-V). Standard calibration/validation measures and validation mean performance for the FM reconstruction are reported in conjunction with Fig. S2 herein; note that the reconstructions do not exhibit amplitude loss in relation to the difference between the calibration and validation period means. The reconstructions are additionally confirmed for use in this analysis by their capacity to resolve known instrumental-period regional EN and LN composite winter temperature patterns (Fig. 1), over a time period that spans both the calibration and validation periods (Kiladis and Diaz, 1989). Other sub-annual reconstruction periods besides FM were evaluated but did not produce good spatial performance in both calibration and validation (cf. WS12 supplemental material, Section III), including December-February, January-March, and March-May, inclusive of the winter and spring periods evaluated in Kiladis and Diaz (1989). Successfully validated reconstruction of FM temperatures is able to take advantage of the fact that late winterearly spring warmth and cold can be expected to have a relationship to tree growth responses via their relationship to early-season moisture availability where snow is a significant contributor to annual moisture availability (cf. Pederson et al., 2011; per. comm, G. Pederson), as is the case in much of the reconstruction region. The FM median reconstruction (cf. Fig. S1) is the focus of this article, covering the period 1500-1980 CE (cf. also Section 3.2).

The instrumental data specifications of EN and LN occurrences are those of Kiladis and Diaz (1989) updated to the present for additional analyses that extend beyond the $1980 \mathrm{CE}$ end of the calibration period using the Multivariate ENSO Index (cf. Fig. 6 caption); these are adjusted $(+1$ year) since they specify the year of onset of the event rather than the period of largest impact that is reflected in our FM temperature target. The primary set of large tropical volcanic eruptions evaluated is that defined by Fischer et al. (2007) over the reconstruction period $1500-1980 \mathrm{CE}(\mathrm{n}=13$, Table $1 \mathrm{a})$, making the results of this paper comparable to the regional spatially-explicit post-volcanic temperature evaluations of Fischer et al. for Europe (cf. Landrum et al., 2013, for discussion). This eruption set, primarily going back to Ammann and Naveau (2003), has been used consistently in the literature of regional spatially-explicit responses to volcanic forcing (Fischer et al., 2007; Anchukaitis et al., 2010; Wegmann et al., 2014), either in its own right (Fischer et al., 2007; Anchukaitis et al., 2010; cf. Cook et al., 2013, who use this data set to evaluate Asia regional-average summer temperature response to volcanic forcing) or in a slightly augmented form (Wegmann et al., 2014). A second set of eruptions, used to evaluate

Table 1a

Years (CE) of large tropical events examined. Derived from Fischer et al. (2007).

\begin{tabular}{lll}
\hline Year CE & Name & Location \\
\hline 1586 & Kelut & Java, Indonesia \\
1595 & Ruiz & Columbia \\
1600 & Huaynaputina & Peru \\
1641 & Parker & Philippines \\
1673 & Gamkonora & Indonesia \\
1809 & unknown & \\
1815 & Tambora & Indonesia \\
$1823^{\text {a }}$ & Galunggung & Indonesia \\
1831 & Babuyan Claro & Indonesia \\
1835 & Cosiguina & Nicaragua \\
$1884^{\text {a }}$ & Krakatau & Indonesia \\
$1903^{\text {a }}$ & Santa Maria & Guatemala \\
1963 & Agung & Indonesia \\
\hline
\end{tabular}

${ }^{\text {a }}$ Indicates adjustment of event year by +1 to account for timing of onset within the year relative to the February-March reconstruction period. 
Table 1b

Additional large tropical events added from Li et al. (2013): those not included in Table 1a which occur after $1500 \mathrm{CE}$, are dated to a specific year by the authors ${ }^{\mathrm{a}}$, and are described as possibility having a Volcanic Explosivity Index $\geq 5$.

\begin{tabular}{lll}
\hline Year CE & Name & Location \\
\hline $1660^{\mathrm{a}}$ & Long Island & New Guinea \\
1680 & Tongkoko & Indonesia \\
1913 & Colima & Mexico \\
\hline
\end{tabular}

a Note that the source cited by Li et al. for their eruption list (http://www.volcano.si.edu/ world/largeeruptions.cfm) gives 1660 for Long Island as radiocarbon dated.

post-volcanic response of the ENSO system by Li et al. (2013) in conjunction with the most recent, longest, and most skillful reconstruction of ENSO core-region (NINO 3.4) SSTs, is also evaluated. This second set adds three large tropical eruptions that are not included in the Fischer et al. data set: those that occur after $1500 \mathrm{CE}$, are dated to a specific year by the authors, and are described as possibly having a Volcanic Explosivity Index (VEI) $\geq 5$ ( $\mathrm{n}=16$, Tables $1 \mathrm{a} / \mathrm{b}$ ) (cf. Li et al., 2013, SOM, Table S4). It should be noted that the radiative effectiveness of the added eruptions from Li et al. (2013) can potentially be debated in comparison to the Fischer et al. (2007) series in that the Fischer et al. events were derived from ice-core sulfate records that directly reflect stratospheric aerosol forcing in conjunction with geologic evidence of eruption intensity (as measured by VEI) (cf. Table 1 therein), whereas Li et al. (2013) include events based on VEI without consideration of direct aerosol forcing (cf. Table S4 therein).

Superposed epoch analysis (SEA) (e.g., Adams et al., 2003; Fischer et al., 2007; Li et al., 2013) was used to determine the post-volcanic composite responses, in which the composite pattern is formed using temperature anomalies calculated relative to the ten-year climatology immediately preceding the individual events. A lagged pre-event climatology period of years fifteen through six prior to the event was also evaluated for the Fischer et al. eruption set since some of the volcanic events occur within five years of each other; this analysis did not indicate sensitivity to the pre-event climatology.

\section{Results}

\subsection{SEA for primary and secondary eruption sets}

The post-event SEA results for the primary eruption set are shown in Fig. 2. These do not show an EN-like initial response in Years 1-2 after large volcanic events, but rather a distinct warming in the interior West and Southwest in Year 1 coupled with cooling in the eastern portion of the region, especially in the continental interior. In Year 2 the warming diminishes to near mean conditions in the western portion of the region, but the eastern cooling intensifies and shifts southward. Distinct LN-like patterns occur in Years 3-5 (Fig. 2; compare to Fig. 1, lower L), with a slight shift (at the continental scale) to the west and north of the warm feature relative to the LN composite (discussed in Section 4.4). Spatial correlations of the SEA patterns for Years 3-4 with the LN composite (Fig. 1 , lower $\mathrm{L}$ ) are significant $(\mathrm{p}<0.15)$, based on comparison to the correlations observed from a nonparametric Monte Carlo null model ensemble $(n=1000)$ of randomevent-year SEAs. Note that evaluation of the mean-field SEAs from these random-event-year draws indicates that they are near zero in magnitude across the regional domain, which is anticipated as they should asymptotically approach the regional FM climatology. None of the other SEA patterns in Fig. 2 (Years 1-2, 5-6) are significant at this level or at lower p-values with either the LN or EN composites (Fig. 1, $\mathrm{L}$; note that three significance levels are indicated there for the SEA patterns relative to the $\mathrm{LN}$ and EN composites). The strength of pattern correlation needed to achieve a given significance level appears high, but is reasonable considering the normal and direct ENSO teleconnection to western North America; one or the other of the ENSO poles (EN and LN) happens in 45 out of the approximately 100 years evaluated for the instrumental-period composites shown in Fig. 1 (L and upper R). For a post-event year's pattern to separate from this overall tendency requires a relatively strong correlation value.

The post-event SEA results for the second eruption set as suggested by Li et al. (2013) are shown in Fig. 3. A significant early-response ENlike pattern does occur in Years 1-2 in this augmented data set, which is particularly similar to the EN composite for Year 2 (Fig. 3, compare to Fig. 1, upper L). At the same time, highly significant LN-like patterns are also observed for two individual events during Year 1 in both eruption sets (Tables 2,3), which has the effect of dampening the impact of the EN-like response in the SEA composite and its significance (Fig. 1, upper $\mathrm{L}$ ). The strong Year 2 pattern response is driven primarily by the highly significant 1586 and 1913 events (Table 3), in conjunction with three events $(1595,1680$, and 1831$)$ having pattern correlations indicative of over $50 \%$ common variability with the EN composite but which are not significant individually at the $\mathrm{p}<0.15$ level (Table 3; cf. Fig. S6). As in the primary SEA results, a clear LN-like response occurs in post-event Years 3-5, and the pattern correlations with the LN composite are significant at the $\mathrm{p}<0.15$ level or lower for all three years (Fig. 3, compare to Fig. 1, lower L); note that the cooling in the northern to northeastern portion of the region is less strong in the second eruption set in Years 4-5. The significance of these LN patterns in the later post-volcanic period is best underlined by the fact that no individual event exhibits significant EN-like structures in either eruption set during these years (Tables 2, 3).

\subsection{Monte Carlo evaluations related to ENSO teleconnection and reconstruction ensemble variability}

Given the observed variation of ENSO teleconnections to the region (e.g., Diaz et al., 2001), and the possibility that their character may change in time (e.g., Coats et al., 2013), it is important to note that the significance of the post-event SEA pattern correlations is insensitive to the events included in the instrumental-period EN and LN composites. To make this determination, a separate Monte Carlo analysis $(\mathrm{n}=1000)$ was completed for the primary eruption set by randomly excluding twenty percent of the EN and LN events in the derived composites. The medians of the resulting distributions of spatial correlations between these new composites and the post-eruption SEA patterns (Fig. S7) are highly similar to the single values in Fig. 1(L). Only in the case of Years 3 and 4 for LN are the median values larger than the corresponding 85 th percentile $(\mathrm{p}<0.15)$ bounds determined by repeating the analysis with the added Monte Carlo dimension that the SEA patterns compared to the new EN and LN composites are drawn from the random-event-year SEA ensemble (Fig. S7). The same outcomes occur (Fig. S8) when the evaluation is further generalized by adding a third Monte Carlo dimension that incorporates draws from the probabilistic ensemble of reconstruction members (Supplemental material, Section I, Fig. S1; WS12 and supplemental material). Based on the robustness indicated by these evaluations, the analyses presented focus on the median reconstruction results and pattern correlation comparisons with the full set of EN and LN instrumental data, as described in Section 2 and represented in Fig. 1(L).

\subsection{Relative homogeneity of spatial responses over time}

Figs. 4 and 5 evaluate the relative homogeneity of the composite response for each post-event year in terms of the amplitude signal of the SEA composite relative to the noise represented by its standard deviation across the included volcanic events. In relation to the distribution of the same metric determined from the random-event-year SEAs, these signal-to-noise $(\mathrm{S} / \mathrm{N})$ ratios are most highly significant in the portions of the domain with the strongest anomalies during Years 1-3 (in both eruption sets), with Year 3 showing the spatially strongest 

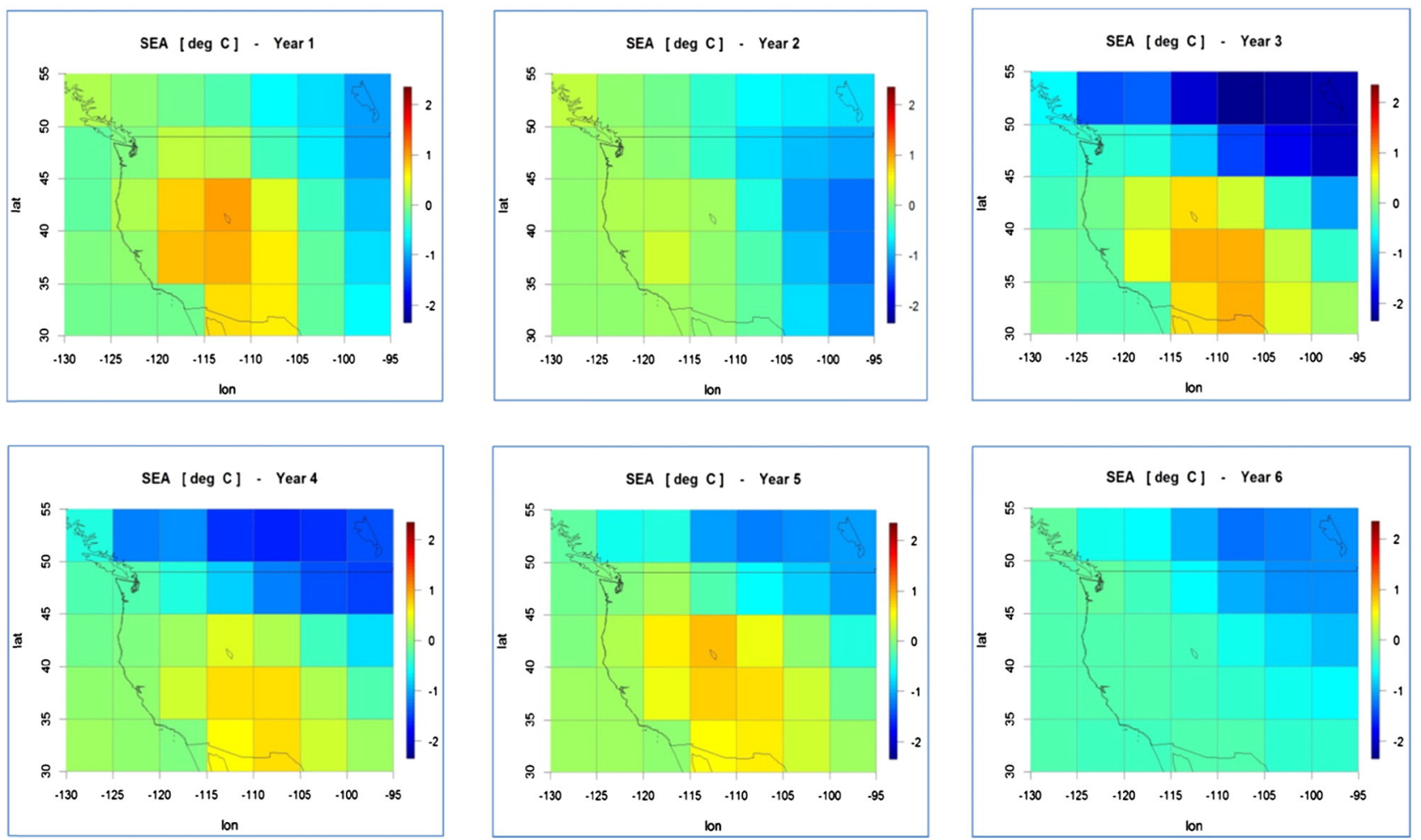

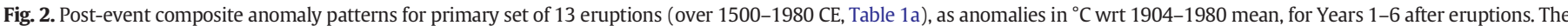

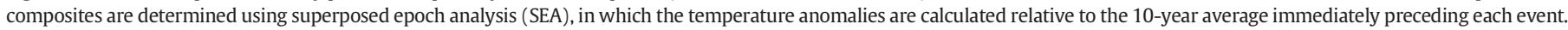

signal. As expected, there is decreasing signal intensity for the following years, although still with relatively strong influence in Year 5 for the second eruption set. Year 3 exhibits the largest number of individual grid cells with relatively strong $(\mathrm{p}<0.15)$ significant $\mathrm{S} / \mathrm{N}$ responses in both sets (Figs. 4, 5, lower R panels). The S/N ratios drop to low and uniformly insignificant values after Year 5 (second set; Fig. 5, lower R panels) or Year 6 (primary set; Fig. 4, lower R panels), reflecting diminishing coherence across events beyond the first half-decade after
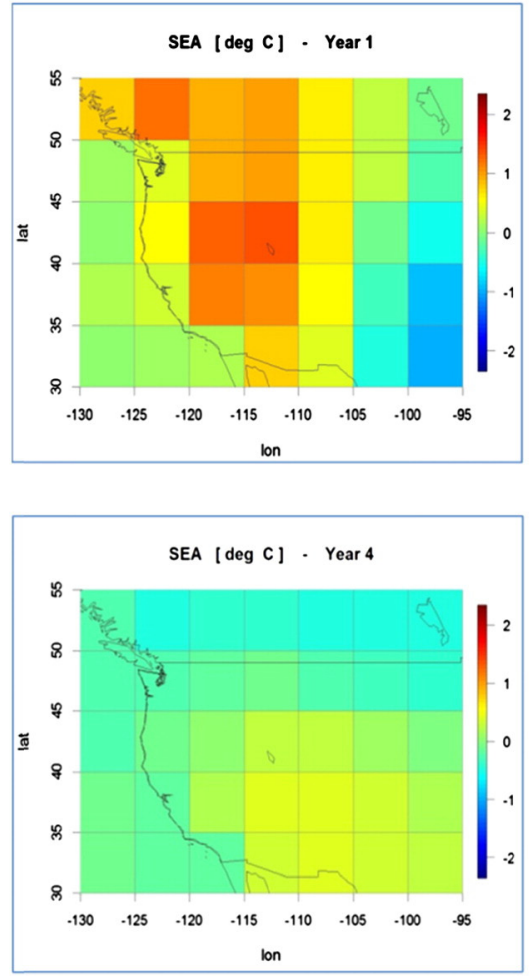
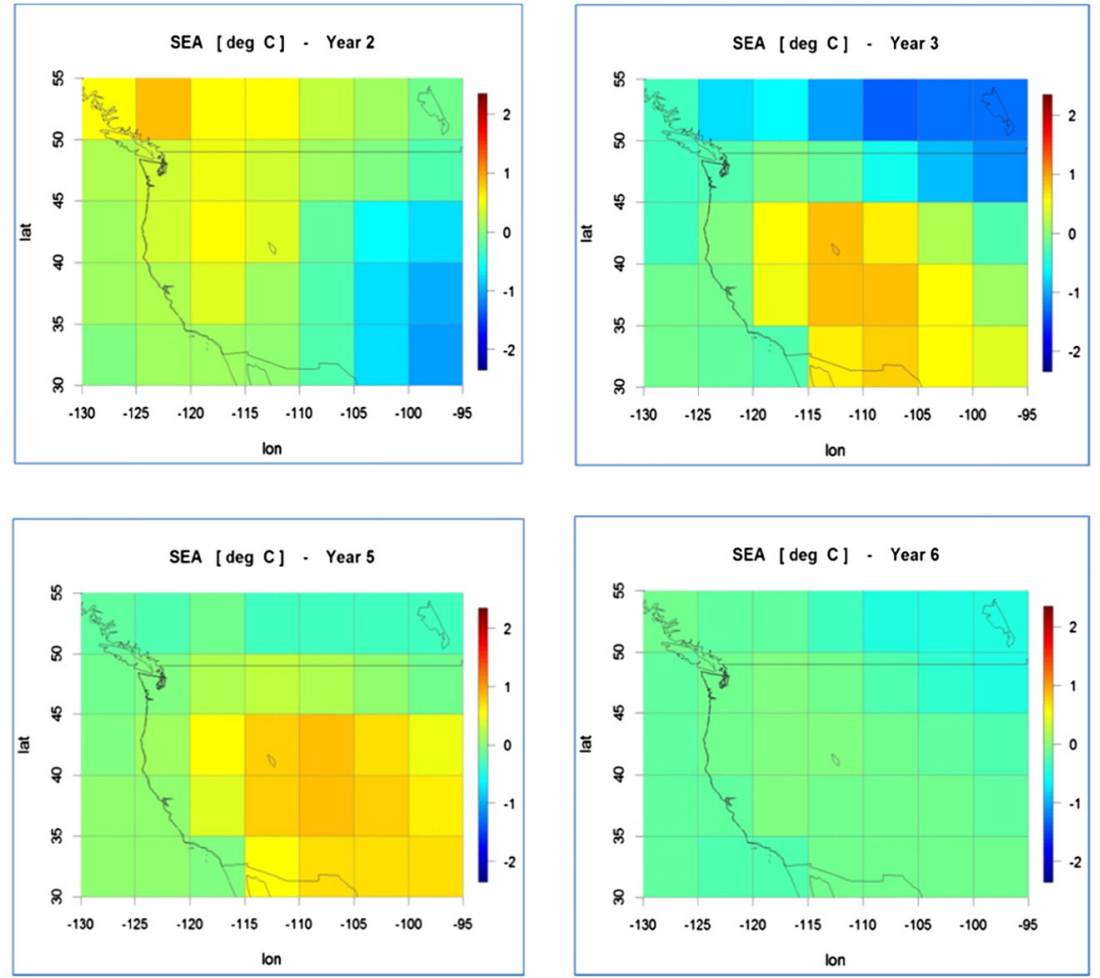

Fig. 3. Same as Fig. 2, except for the second set of 16 evaluated eruptions (Table 1b). 
Table 2

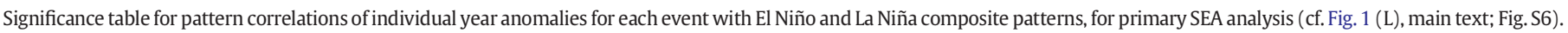
" 0 " indicates non-significance, "YES" indicates significance at indicated p-value levels, underlining indicates correlation $\geq 0.90^{\mathrm{a}}$.

\begin{tabular}{|c|c|c|c|c|c|c|c|c|c|c|c|c|c|c|c|c|c|}
\hline \multicolumn{9}{|c|}{ El Niño $\mathrm{p}<0.15$ level } & \multicolumn{9}{|c|}{ El Niño $\mathrm{p}<0.10$ level } \\
\hline & Yr1 & Yr2 & Yr3 & Yr4 & Yr5 & Yr6 & Yr7 & Yr8 & & Yr1 & Yr2 & Yr3 & Yr4 & Yr5 & Yr6 & Yr7 & Yr8 \\
\hline 1586 & 0 & YES & 0 & 0 & 0 & 0 & 0 & YES & 1586 & 0 & YES & 0 & 0 & 0 & 0 & 0 & 0 \\
\hline 1595 & 0 & $\overline{0}$ & 0 & 0 & 0 & 0 & 0 & 0 & 1595 & 0 & $\overline{0}$ & 0 & 0 & 0 & 0 & 0 & 0 \\
\hline 1600 & 0 & 0 & 0 & 0 & 0 & YES & 0 & YES & 1600 & 0 & 0 & 0 & 0 & 0 & 0 & 0 & 0 \\
\hline 1641 & 0 & 0 & 0 & 0 & 0 & 0 & 0 & 0 & 1641 & 0 & 0 & 0 & 0 & 0 & 0 & 0 & 0 \\
\hline 1673 & 0 & 0 & 0 & 0 & 0 & YES & 0 & YES & 1673 & 0 & 0 & 0 & 0 & 0 & YES & 0 & YES \\
\hline 1809 & 0 & 0 & 0 & 0 & 0 & $\overline{0}$ & 0 & $\overline{0}$ & 1809 & 0 & 0 & 0 & 0 & 0 & $\overline{0}$ & 0 & $\overline{0}$ \\
\hline 1815 & YES & 0 & 0 & 0 & 0 & 0 & 0 & 0 & 1815 & YES & 0 & 0 & 0 & 0 & 0 & 0 & 0 \\
\hline 1823 & $\overline{0}$ & 0 & 0 & 0 & 0 & 0 & 0 & 0 & 1823 & $\overline{0}$ & 0 & 0 & 0 & 0 & 0 & 0 & 0 \\
\hline 1831 & 0 & 0 & 0 & 0 & 0 & 0 & 0 & 0 & 1831 & 0 & 0 & 0 & 0 & 0 & 0 & 0 & 0 \\
\hline 1835 & 0 & 0 & 0 & 0 & 0 & 0 & 0 & 0 & 1835 & 0 & 0 & 0 & 0 & 0 & 0 & 0 & 0 \\
\hline 1884 & YES & 0 & 0 & 0 & 0 & 0 & 0 & 0 & 1884 & YES & 0 & 0 & 0 & 0 & 0 & 0 & 0 \\
\hline 1903 & 0 & 0 & 0 & 0 & 0 & 0 & 0 & 0 & 1903 & 0 & 0 & 0 & 0 & 0 & 0 & 0 & 0 \\
\hline 1963 & 0 & 0 & 0 & 0 & 0 & 0 & 0 & 0 & 1963 & 0 & 0 & 0 & 0 & 0 & 0 & 0 & 0 \\
\hline
\end{tabular}

La Niña $\mathrm{p}<0.15$ level

La Niña $\mathrm{p}<0.10$ level

\begin{tabular}{|c|c|c|c|c|c|c|c|c|c|c|c|c|c|c|c|c|c|}
\hline & Yr1 & Yr2 & Yr3 & Yr4 & Yr5 & Yr6 & Yr7 & Yr8 & & Yr1 & Yr2 & Yr3 & Yr4 & Yr5 & Yr6 & Yr7 & Yr8 \\
\hline 1586 & 0 & 0 & YES & YES & 0 & 0 & YES & 0 & 1586 & 0 & 0 & 0 & 0 & 0 & 0 & 0 & 0 \\
\hline 1595 & 0 & 0 & 0 & YES & YES & 0 & 0 & 0 & 1595 & 0 & 0 & 0 & YES & YES & 0 & 0 & 0 \\
\hline 1600 & 0 & 0 & 0 & $\overline{0}$ & 0 & 0 & 0 & 0 & 1600 & 0 & 0 & 0 & $\overline{0}$ & 0 & 0 & 0 & 0 \\
\hline 1641 & 0 & 0 & 0 & YES & 0 & YES & YES & 0 & 1641 & 0 & 0 & 0 & YES & 0 & 0 & YES & 0 \\
\hline 1673 & 0 & 0 & YES & 0 & 0 & 0 & $\overline{0}$ & 0 & 1673 & 0 & 0 & 0 & 0 & 0 & 0 & 0 & 0 \\
\hline 1809 & 0 & 0 & 0 & 0 & 0 & 0 & 0 & 0 & 1809 & 0 & 0 & 0 & 0 & 0 & 0 & 0 & 0 \\
\hline 1815 & 0 & 0 & 0 & 0 & 0 & 0 & 0 & 0 & 1815 & 0 & 0 & 0 & 0 & 0 & 0 & 0 & 0 \\
\hline 1823 & 0 & 0 & 0 & 0 & 0 & 0 & 0 & 0 & 1823 & 0 & 0 & 0 & 0 & 0 & 0 & 0 & 0 \\
\hline 1831 & 0 & 0 & YES & 0 & YES & 0 & YES & YES & 1831 & 0 & 0 & YES & 0 & YES & 0 & YES & 0 \\
\hline 1835 & YES & 0 & $\overline{\mathrm{YES}}$ & YES & $\overline{0}$ & 0 & $\overline{0}$ & 0 & 1835 & YES & 0 & $\overline{\mathrm{YES}}$ & 0 & $\overline{0}$ & 0 & $\overline{0}$ & 0 \\
\hline 1884 & $\overline{0}$ & 0 & $\overline{\mathrm{YES}}$ & 0 & 0 & YES & 0 & 0 & 1884 & $\overline{0}$ & 0 & $\overline{0}$ & 0 & 0 & YES & 0 & 0 \\
\hline 1903 & YES & 0 & 0 & 0 & 0 & $\overline{0}$ & 0 & 0 & 1903 & YES & 0 & 0 & 0 & 0 & $\overline{0}$ & 0 & 0 \\
\hline 1963 & $\overline{0}$ & 0 & 0 & 0 & 0 & 0 & 0 & 0 & 1963 & $\overline{0}$ & 0 & 0 & 0 & 0 & 0 & 0 & 0 \\
\hline \multirow{2}{*}{\multicolumn{3}{|c|}{ El Niño $\mathrm{p}<0.15$ level }} & \multirow{2}{*}{\multicolumn{2}{|c|}{$\begin{array}{l}\text { Yr } 1 \\
0.738\end{array}$}} & \multicolumn{2}{|c|}{ Yr 2} & \multicolumn{2}{|c|}{ Yr 3} & \multicolumn{2}{|l|}{ Yr 4} & \multicolumn{2}{|l|}{ Yr 5} & \multicolumn{2}{|l|}{ Yr 6} & \multicolumn{2}{|l|}{ Yr 7} & Yr 8 \\
\hline & & & & & \multirow{2}{*}{\multicolumn{2}{|c|}{$\begin{array}{l}0.741 \\
\text { Yr 2 }\end{array}$}} & \multicolumn{2}{|c|}{0.736} & \multicolumn{2}{|l|}{0.714} & \multicolumn{2}{|l|}{0.729} & \multicolumn{2}{|l|}{0.712} & \multicolumn{2}{|l|}{0.699} & 0.681 \\
\hline \multirow{2}{*}{\multicolumn{3}{|c|}{ El Niño $\mathrm{p}<0.10$ level }} & \multicolumn{2}{|c|}{ Yr 1} & & & \multicolumn{2}{|c|}{ Yr 3} & \multicolumn{2}{|l|}{ Yr 4} & \multicolumn{2}{|l|}{ Yr 5} & \multicolumn{2}{|l|}{ Yr 6} & \multicolumn{2}{|l|}{ Yr 7} & Yr 8 \\
\hline & & & \multicolumn{2}{|c|}{0.828} & \multicolumn{2}{|c|}{0.816} & & & \multicolumn{2}{|l|}{0.802} & \multicolumn{2}{|l|}{0.814} & 0.799 & & 0.800 & & 0.777 \\
\hline \multirow{2}{*}{\multicolumn{3}{|c|}{ La Niña $\mathrm{p}<0.15$ level }} & \multicolumn{2}{|c|}{ Yr 1} & \multicolumn{2}{|c|}{ Yr 2} & \multicolumn{2}{|c|}{ Yr 3} & Yr 4 & & Yr 5 & & Yr 6 & & Yr 7 & & Yr 8 \\
\hline & & & & & & & & & 0.745 & & 0.748 & & 0.759 & & 0.774 & & 0.747 \\
\hline La Niî & $<0.10$ & & & & & & & & Yr 4 & & Yr 5 & & Yr 6 & & Yr 7 & & Yr 8 \\
\hline & & & & & & & & & 0.860 & & 0.849 & & 0.841 & & 0.829 & & 0.834 \\
\hline
\end{tabular}

a Significance thresholds are shown below, rounded to 3 significant digits, determined from individual year anomalies for each event taken from the random-event-year SEA ensemble.

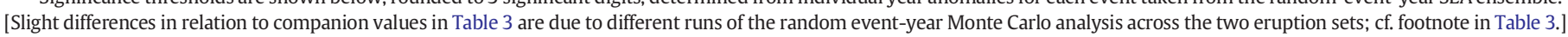

the eruption, even though individual events may continue to show significant EN- and LN-like patterns in these later years (Tables 2, 3) and the composite SEA patterns may exhibit EN- and LN-like features (Figs. 4, 5, upper L panels). Additional confirmation of the robust nature of the Year 3 maximum signal is described in the Supplemental material; cf. Figs. S7 and S8, and associated text describing these (p. 5).

\section{Summary and discussion}

\subsection{Summary}

The results described are broadly consistent with the hypothesis that large tropical eruptions impose a radiative forcing that stimulates the coupled climate system to a probabilistic tendency towards an initial EN response followed by a later LN response (Adams et al., 2003; Mann et al., 2005; Emile-Geay et al., 2008; D'Arrigo et al., 2009; Wilson et al., 2010; Li et al., 2013). A significant regional spatial expression of an EN-type pattern in Years 1 and 2 is nevertheless dependent on the eruption set evaluated, not occurring in the primary event set evaluated but evidenced in the second set (Figs. 2, 3; Fig. 1, upper L). Within that context, the regional SEA composite is driven by a few highly significant individual events (Table 3 ) in conjunction with a few less-strongly significant ones during Year 2, while strongly significant LN-type patterns also occur in Year 1 in both eruption sets (Tables 2 and 3). In contrast, a clear and significant LN-type spatial pattern is observed in Years 3-5 in both eruption sets (Figs. 2, 3; Fig. 1, lower L), while no significant composite or single individual-event EN-type pattern is observed during these three years (Fig. 1, upper L; Tables 2, 3). The strength of the post-event LN-type response peaks in Year 3, both in terms of the number of individual events showing significant responses (Tables 2, 3) and in terms of strongest grid cell-level spatial significance (Figs. 4, 5, lower $\mathrm{R}$ panels). The spatial composite post-event signal weakens to insignificance in terms of evaluated $\mathrm{S} / \mathrm{N}$ ratios for both data sets in the second half-decade after an eruption, starting in Year 6 for the primary eruption set and in Year 5 for the second eruption set.

\subsection{Relation of post-volcanic temperature response to atmospheric circulation}

In order to evaluate the SEA temperature results in terms of the larger-scale circulation and to compare them with natural climate variability, a FM $500 \mathrm{mb}$ geopotential height anomaly composite for LN events since 1950 CE is shown in Fig. 6, indicating a strong PacificNorth America (PNA)-type pattern associated with a relatively weak negative NAO-like pattern (cf. figure caption for corresponding EN composite features). This composite is derived from the Twentieth Century Reanalysis v2 ("20CR") (Compo et al., 2011); a highly similar pattern results from using the NCEP/NCAR Reanalysis for the same 
Table 3

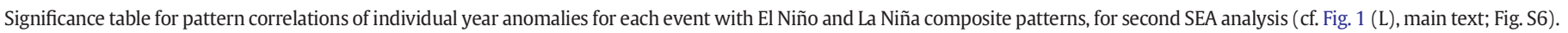
"0" indicates non-significance, "YES" indicates significance at indicated p-value levels, underlining indicates correlation $\geq 0.90^{\mathrm{a}}$.

\begin{tabular}{|c|c|c|c|c|c|c|c|c|c|c|c|c|c|c|c|c|c|}
\hline \multicolumn{9}{|c|}{ El Niño $\mathrm{p}<0.15$ level } & \multicolumn{9}{|c|}{ El Niño $\mathrm{p}<0.10$ level } \\
\hline & Yr1 & Yr2 & Yr3 & Yr4 & Yr5 & Yr6 & Yr7 & Yr8 & & Yr1 & Yr2 & Yr3 & Yr4 & Yr5 & Yr6 & Yr7 & Yr8 \\
\hline 1586 & 0 & YES & 0 & 0 & 0 & 0 & 0 & YES & 1586 & 0 & YES & 0 & 0 & 0 & 0 & 0 & 0 \\
\hline 1595 & 0 & $\overline{0}$ & 0 & 0 & 0 & 0 & 0 & 0 & 1595 & 0 & $\overline{0}$ & 0 & 0 & 0 & 0 & 0 & 0 \\
\hline 1600 & 0 & 0 & 0 & 0 & 0 & YES & 0 & YES & 1600 & 0 & 0 & 0 & 0 & 0 & 0 & 0 & 0 \\
\hline 1641 & 0 & 0 & 0 & 0 & 0 & 0 & 0 & 0 & 1641 & 0 & 0 & 0 & 0 & 0 & 0 & 0 & 0 \\
\hline 1660 & 0 & 0 & 0 & 0 & 0 & 0 & 0 & 0 & 1660 & 0 & 0 & 0 & 0 & 0 & 0 & 0 & 0 \\
\hline 1673 & 0 & 0 & 0 & 0 & 0 & YES & 0 & YES & 1673 & 0 & 0 & 0 & 0 & 0 & YES & 0 & YES \\
\hline 1680 & YES & 0 & 0 & 0 & 0 & 0 & 0 & $\overline{0}$ & 1680 & YES & 0 & 0 & 0 & 0 & 0 & 0 & $\overline{0}$ \\
\hline 1809 & 0 & 0 & 0 & 0 & 0 & 0 & 0 & 0 & 1809 & $\overline{0}$ & 0 & 0 & 0 & 0 & 0 & 0 & 0 \\
\hline 1815 & YES & 0 & 0 & 0 & 0 & 0 & 0 & 0 & 1815 & YES & 0 & 0 & 0 & 0 & 0 & 0 & 0 \\
\hline 1823 & $\overline{0}$ & 0 & 0 & 0 & 0 & 0 & 0 & 0 & 1823 & $\overline{0}$ & 0 & 0 & 0 & 0 & 0 & 0 & 0 \\
\hline 1831 & 0 & 0 & 0 & 0 & 0 & 0 & 0 & 0 & 1831 & 0 & 0 & 0 & 0 & 0 & 0 & 0 & 0 \\
\hline 1835 & 0 & 0 & 0 & 0 & 0 & 0 & 0 & 0 & 1835 & 0 & 0 & 0 & 0 & 0 & 0 & 0 & 0 \\
\hline 1884 & YES & 0 & 0 & 0 & 0 & 0 & 0 & 0 & 1884 & YES & 0 & 0 & 0 & 0 & 0 & 0 & 0 \\
\hline 1903 & 0 & 0 & 0 & 0 & 0 & 0 & 0 & 0 & 1903 & 0 & 0 & 0 & 0 & 0 & 0 & 0 & 0 \\
\hline 1913 & YES & YES & 0 & 0 & 0 & 0 & 0 & 0 & 1913 & 0 & YES & 0 & 0 & 0 & 0 & 0 & 0 \\
\hline 1963 & 0 & $\overline{0}$ & 0 & 0 & 0 & 0 & 0 & 0 & 1963 & 0 & $\overline{0}$ & 0 & 0 & 0 & 0 & 0 & 0 \\
\hline \multicolumn{9}{|c|}{ La Niña $\mathrm{p}<0.15$ level } & \multicolumn{9}{|c|}{ La Niña $\mathrm{p}<0.10$ level } \\
\hline & Yr1 & Yr2 & Yr3 & Yr4 & Yr5 & Yr6 & Yr7 & Yr8 & & Yr1 & Yr2 & Yr3 & Yr4 & Yr5 & Yr6 & Yr7 & Yr8 \\
\hline 1586 & 0 & 0 & YES & YES & 0 & 0 & YES & 0 & 1586 & 0 & 0 & 0 & 0 & 0 & 0 & 0 & 0 \\
\hline 1595 & 0 & 0 & 0 & YES & YES & 0 & 0 & 0 & 1595 & 0 & 0 & 0 & YES & YES & 0 & 0 & 0 \\
\hline 1600 & 0 & 0 & 0 & $\overline{0}$ & 0 & 0 & 0 & 0 & 1600 & 0 & 0 & 0 & $\overline{0}$ & 0 & 0 & 0 & 0 \\
\hline 1641 & 0 & 0 & 0 & YES & 0 & YES & YES & 0 & 1641 & 0 & 0 & 0 & yes & 0 & 0 & YES & 0 \\
\hline 1660 & 0 & 0 & 0 & 0 & 0 & 0 & $\overline{0}$ & 0 & 1660 & 0 & 0 & 0 & 0 & 0 & 0 & $\overline{0}$ & 0 \\
\hline 1673 & 0 & 0 & YES & 0 & 0 & 0 & 0 & 0 & 1673 & 0 & 0 & 0 & 0 & 0 & 0 & 0 & 0 \\
\hline 1680 & 0 & 0 & 0 & 0 & 0 & 0 & 0 & 0 & 1680 & 0 & 0 & 0 & 0 & 0 & 0 & 0 & 0 \\
\hline 1809 & 0 & 0 & 0 & 0 & 0 & 0 & 0 & 0 & 1809 & 0 & 0 & 0 & 0 & 0 & 0 & 0 & 0 \\
\hline 1815 & 0 & 0 & 0 & 0 & 0 & 0 & 0 & 0 & 1815 & 0 & 0 & 0 & 0 & 0 & 0 & 0 & 0 \\
\hline 1823 & 0 & 0 & 0 & 0 & 0 & 0 & 0 & 0 & 1823 & 0 & 0 & 0 & 0 & 0 & 0 & 0 & 0 \\
\hline 1831 & 0 & 0 & YES & 0 & YES & 0 & YES & YES & 1831 & 0 & 0 & YES & 0 & YES & 0 & YES & 0 \\
\hline 1835 & YES & 0 & $\overline{\mathrm{YES}}$ & yes & $\overline{0}$ & 0 & $\overline{0}$ & 0 & 1835 & YES & 0 & $\overline{\mathrm{YES}}$ & 0 & $\overline{0}$ & 0 & $\overline{0}$ & 0 \\
\hline 1884 & $\overline{0}$ & 0 & $\overline{\mathrm{YES}}$ & 0 & 0 & YES & 0 & 0 & 1884 & $\overline{0}$ & 0 & $\overline{0}$ & 0 & 0 & YES & 0 & 0 \\
\hline 1903 & YES & 0 & 0 & 0 & 0 & $\overline{0}$ & 0 & 0 & 1903 & YES & 0 & 0 & 0 & 0 & $\overline{0}$ & 0 & 0 \\
\hline 1913 & $\overline{0}$ & 0 & 0 & 0 & 0 & 0 & 0 & 0 & 1913 & $\overline{0}$ & 0 & 0 & 0 & 0 & 0 & 0 & 0 \\
\hline 1963 & 0 & 0 & 0 & 0 & 0 & 0 & 0 & 0 & 1963 & 0 & 0 & 0 & 0 & 0 & 0 & 0 & 0 \\
\hline \multirow{2}{*}{\multicolumn{3}{|c|}{ El Niño $\mathrm{p}<0.15$ level }} & \multicolumn{2}{|c|}{ Yr 1} & \multicolumn{2}{|c|}{ Yr 2} & \multicolumn{2}{|c|}{ Yr 3} & \multicolumn{2}{|l|}{ Yr 4} & \multicolumn{2}{|l|}{ Yr 5} & \multicolumn{2}{|l|}{ Yr 6} & \multicolumn{2}{|l|}{ Yr 7} & Yr 8 \\
\hline & & & \multicolumn{2}{|c|}{0.734} & \multicolumn{2}{|c|}{0.741} & \multicolumn{2}{|c|}{0.731} & \multicolumn{2}{|l|}{0.707} & \multicolumn{2}{|l|}{0.713} & \multicolumn{2}{|l|}{0.709} & 0.698 & & 0.681 \\
\hline El Niñ & $<0.10$ & & & & & & & & Yr 4 & & Yr 5 & & Yr 6 & & Yr 7 & & Yr 8 \\
\hline & & & & & & & & & 0.800 & & 0.801 & & 0.797 & & 0.793 & & 0.777 \\
\hline La Niñ & $<0.15$ & & & & & & & & Yr 4 & & Yr 5 & & Yr 6 & & Yr 7 & & Yr 8 \\
\hline & & & & & & & & & 0.756 & & 0.748 & & 0.761 & & 0.774 & & 0.754 \\
\hline La Niñ & $<0.10$ & & & & & & & & $\operatorname{Yr} 4$ & & Yr 5 & & Yr 6 & & Yr 7 & & Yr 8 \\
\hline & & & & & & & & & 0.862 & & 0.849 & & 0.845 & & 0.838 & & 0.837 \\
\hline
\end{tabular}

a Significance thresholds are shown below, rounded to 3 significant digits, determined from individual year anomalies for each event taken from the random-event-year SEA ensemble.

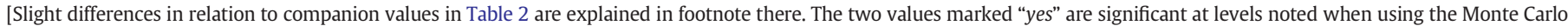

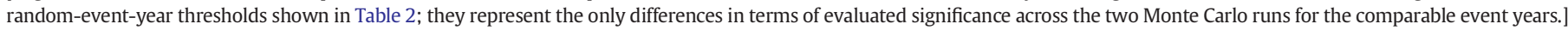

years (not shown). Comparable instrumental-period post-volcanic FM pressure composites for post-event Years $0-2$ are shown in Fig. 7, which include the three most recent events in the SEA analysis (Krakatau, Santa Maria, and Agung; cf. Table 1a). The post-1980 El Chichón and Pinatubo events are excluded from the composite for Years 0-2 to guard against the chance that ongoing El Niños might contaminate the signal (cf. Robock et al, 1995). For Years 3-7 (Fig. 7) these events were included because the initially existing EN state of the tropical Pacific had time to subside and the effect of the post-eruption dynamics could take on more salience. The 20CR post-event pressure composite does not exhibit a typical EN-like pattern in Year 1; it includes a distinct negative anomaly over nearly all of North America, and anomalous high pressure over the North Pacific coupled with anomalous low pressure in northwestern North America that is more similar to the LN composite (Fig. 6). This overall result is not changed if the influence of the existing El Niños associated with the El Chichón and Pinatubo is introduced into the composite, with the exception that more EN-reminiscent anomalous low pressure occurs in the North Pacific in association with the anomalous low pressure over nearly all of North America (not shown). In Year 2 a somewhat LN-like pressure pattern is exhibited in the northeastern Pacific, North America, and the North Atlantic, although the anomalies in temperate western and southeastern North America and the northeastern Pacific are less strong than those in the LN composite. By Year 3, a strongly LN-like pressure composite occurs in the North Pacific, North America, and the North Atlantic. Related structures occur in the North Pacific and North America in Year 4, with a northeastward shift and expansion of the low-pressure anomaly over North America, which connects with a low-pressure anomaly over northwestern Europe that represents the northern component of a reversal in the North Atlantic to a positive NAO-like pattern. Years 5-7 exhibit more random variability, as further relaxation from the volcanicevent effects occurs.

Non-coherence of the Year 1 circulation pattern with ENSO-like conditions is consistent with the weak SEA pattern correlations that this initial year after the eruptions exhibits with the EN/LN temperature composites for the primary eruption set (Fig. 1, L), whereas it is less consistent with the initial EN-like SEA temperature patterns exhibited by the second eruption set in Year 1 (Fig. 1, L). The somewhat LN-like 
Year 1

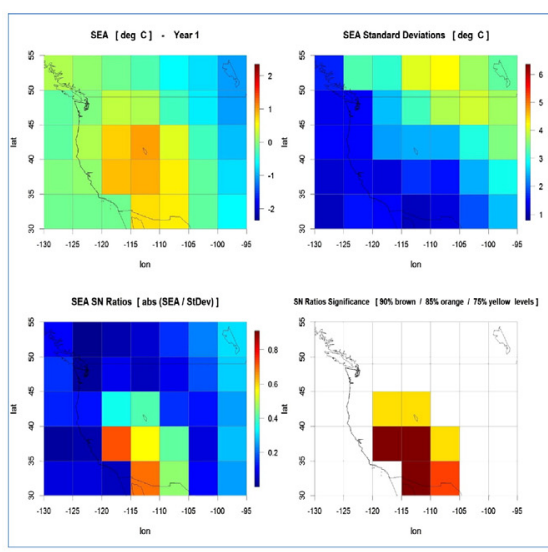

Year 5

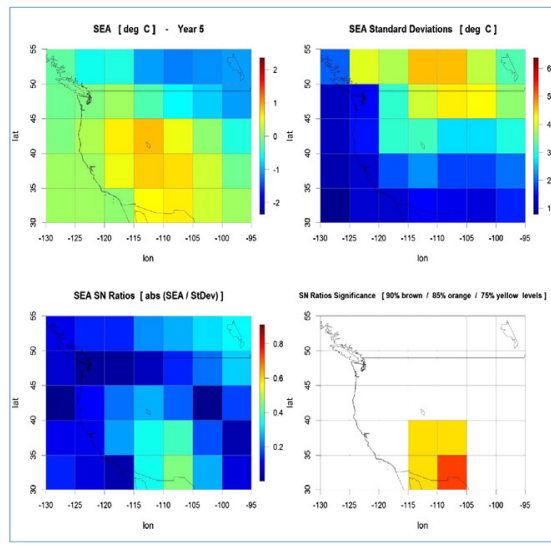

Year 2
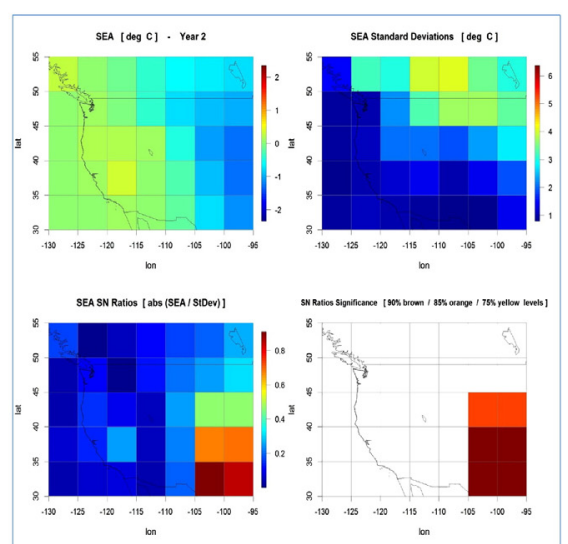

Year 6
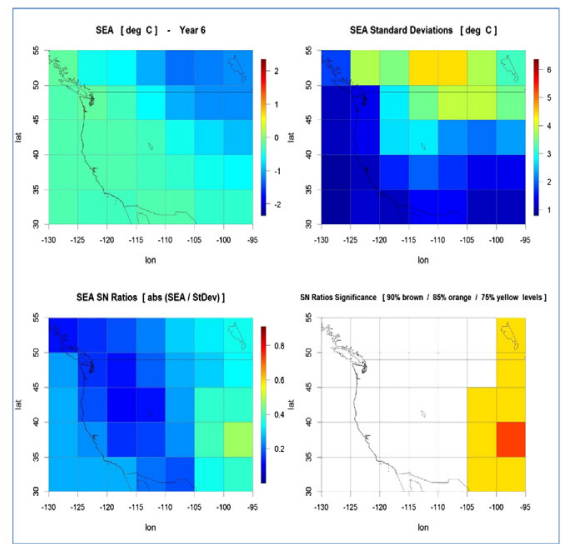

Year 3
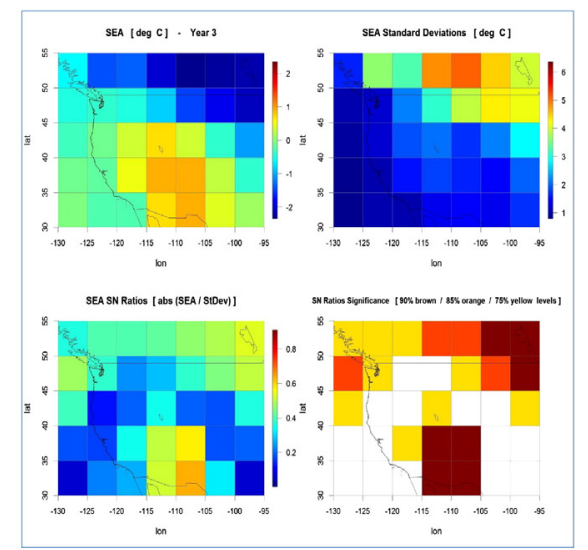

Year 7
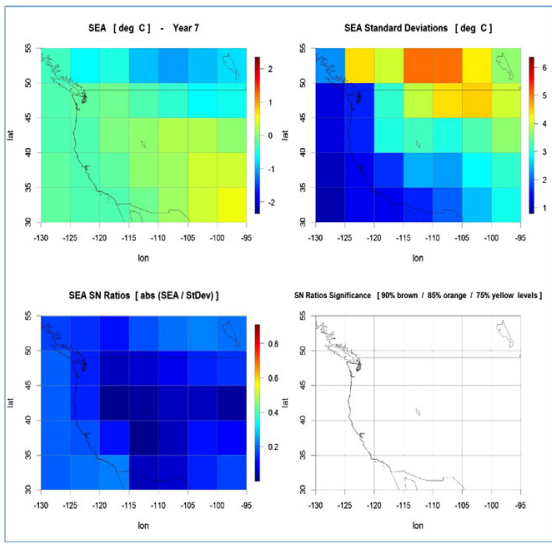

Year 4
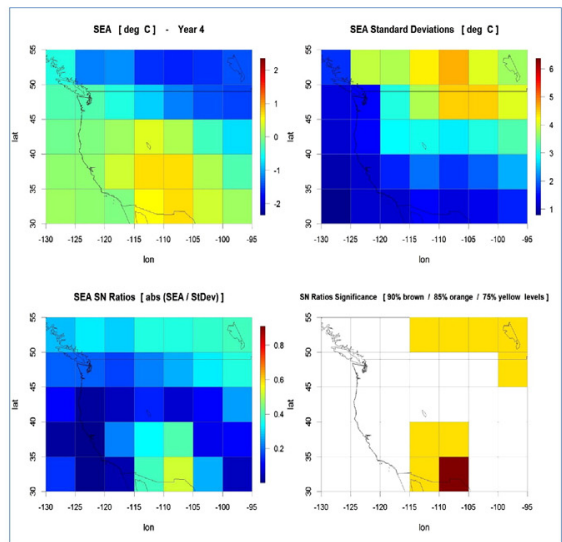

Year 8
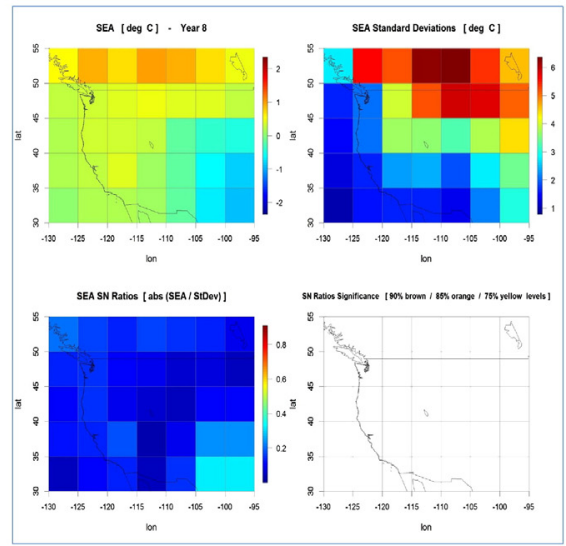

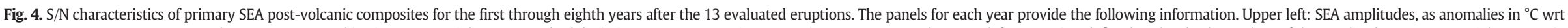

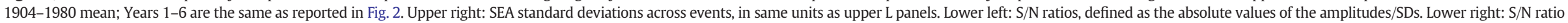

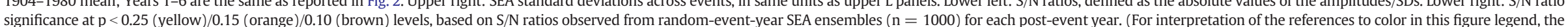
reader is referred to the web version of this article.) 
Year 1

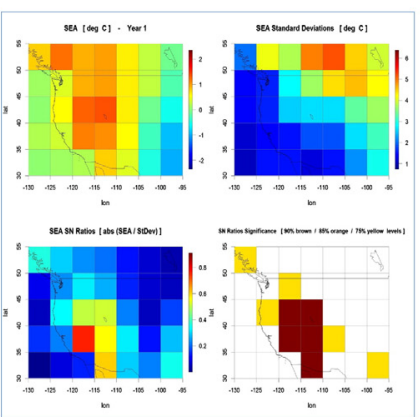

Year 5

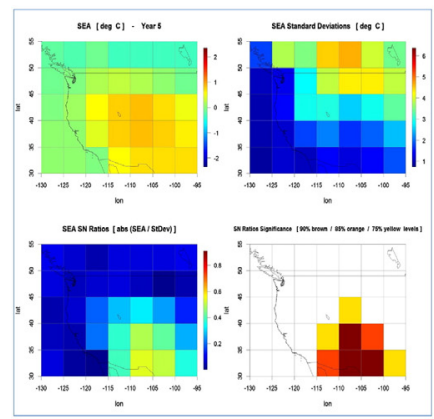

Year 2

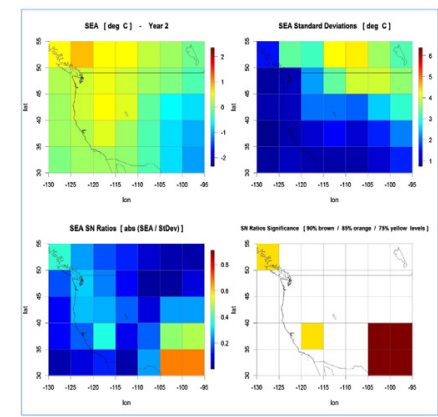

Year 6

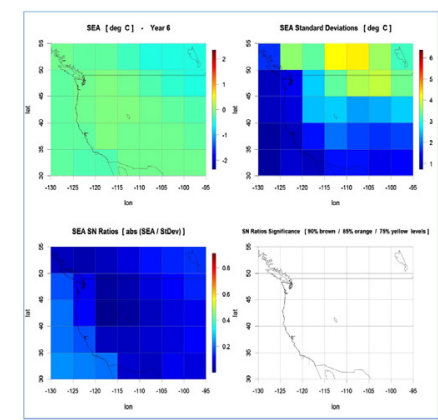

Year 3

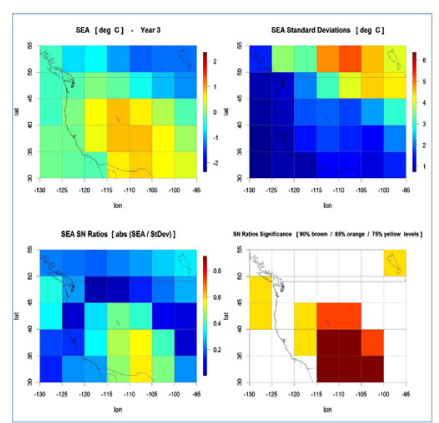

Year 7

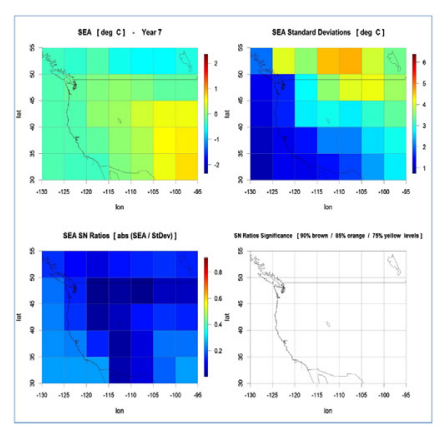

Year 4

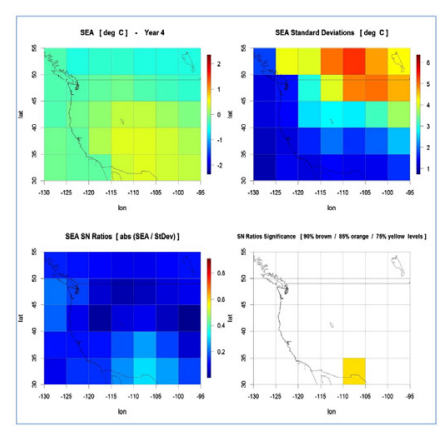

Year 8

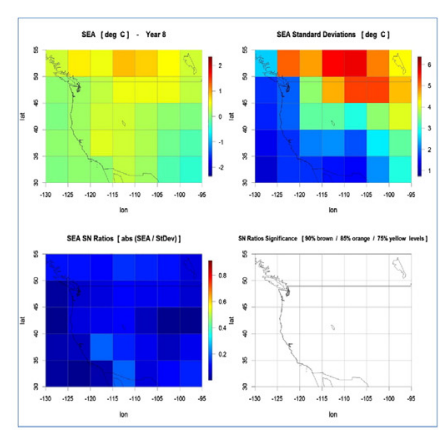

SEAs (upper left)

SDs (upper right)

SN Ratios (lower left)

Significance relative to random SEA years (lower right)

Fig. 5. Same as Fig. 4, except for the second set of 16 evaluated eruptions. Information in upper L panels for Years 1-6 is the same as reported in Fig. 3.

Year 2 circulation pattern is largely inconsistent with the SEA pattern correlation results for both eruption sets (Fig. 1, L). Although based on a shorter instrumental record, these observations additionally indicate a relatively non-robust character of the Year 1-2 late winter response in relation to ENSO patterns in the study region. In contrast, the strongly LN-like pressure composite in North America and the adjacent Pacific and Atlantic regions in Year 3 is consistent with the robust LN-like temperature response for that year in both eruption sets (Fig. 1, lower L; Figs. 4, 5, upper L panels; Tables 2, 3; Figs. S7, S8). This coherence is further illustrated by the maximum $\mathrm{S} / \mathrm{N}$ pattern significance occurring in this year (Figs. 4, 5, lower R panels), suggesting a maximum consistency in the regional strength of the dynamic circulation-to-surface temperature linkage at this time across the post-event years examined. The progressively declining coherence across eruptions as post-event time progresses beyond Year 3, indicated by the $\mathrm{S} / \mathrm{N}$ data (Figs. 4, 5, lower $\mathrm{R}$ panels), is also consistent with the less LN-like pressure composite for Year 4 and the more spatially variable pressure composites after that time.

\subsection{Additional considerations concerning the post-volcanic response of the ENSO system}

In general, our results are in best agreement with those presented by Wilson et al. (2010), who also find an early EN-like response that is conditional on the eruption set used and a more robust LN-like response in subsequent years. We note that the two eruption sets used by Wilson et al. ( $\mathrm{n}=10, \mathrm{n}=4$ ) include fewer events than those used herein and extend back only to 1800 . Additionally, the timing of the later LN-like response is more heterogeneous across the four reconstruction SEAs they evaluate. In contrast, the conditional nature of the regional late winter EN-like temperature response we find in Years 1 and 2 partially differs from the cold season (October-March) Niño 3 reconstruction SEA of Adams et al. (2003), who find a more robust early EN-like response in conjunction with a clear and relatively long-lasting delayed
LN-like response using a global pattern analysis. Our results also partially differ from the recently published late fall to mid-winter (NovemberJanuary) Niño 3.4 reconstruction SEA of Li et al. (2013), who find a strong early EN-like response along with a distinctly weaker (in terms of amplitude and significance) delayed LN-like cooling. The lack of robustness we find for an initial post-event EN-like temperature signal is supported by the $20 \mathrm{CR}$ pressure composite analysis presented. It should be noted, however, that the EN-like Year 1 temperature responses for Tambora and Krakatau (Tables 2, 3; Fig. S6) suggest that particularly strong eruptions could align (in a probabilistic sense) the initial postevent circulation-surface temperature linkage in North America and the adjacent Pacific with the tendency to post-event EN-like SST conditions in the tropical Pacific, as noted by Emile-Geay et al. (2008). Overall, our temperature SEA results and 20CR pressure analysis argue against a hypothesis that an initial EN-like response is generally required to stimulate a subsequent LN-like response a few years later (Adams et al., 2003; Mann et al., 2005; Emile-Geay et al., 2008; cf. Wilson et al., 2010). Rather, we see clear evidence for a systematic dynamical mechanism that is at least as strong and which engages as the system recovers towards pre-eruption radiative conditions, described below. The individual event results (Tables 2, 3) are consistent with this interpretation: for both eruption sets only one of the five events that exhibits significant $(\mathrm{p}<0.15)$ LN-like patterns in Year 3 (Krakatau) is preceded by a significant EN-like pattern in Year 1, similarly only one significant Year 3 LN-like pattern is preceded by a significant EN-like pattern in Year 2 (Kelut).

More generally, the forcing imposed on the climate system by large, explosive volcanic eruptions that inject substantial amounts of sulfur into the stratosphere not only influences the circulation (in both the atmosphere and potentially the ocean through ENSO), but by definition it first and fundamentally reduces the energy (heat) in the Earth system by increasing the amount of solar radiation reflected back to space. This effect is the cause of the immediate and robust cooling in global temperatures that occurs within the months following an eruption, 


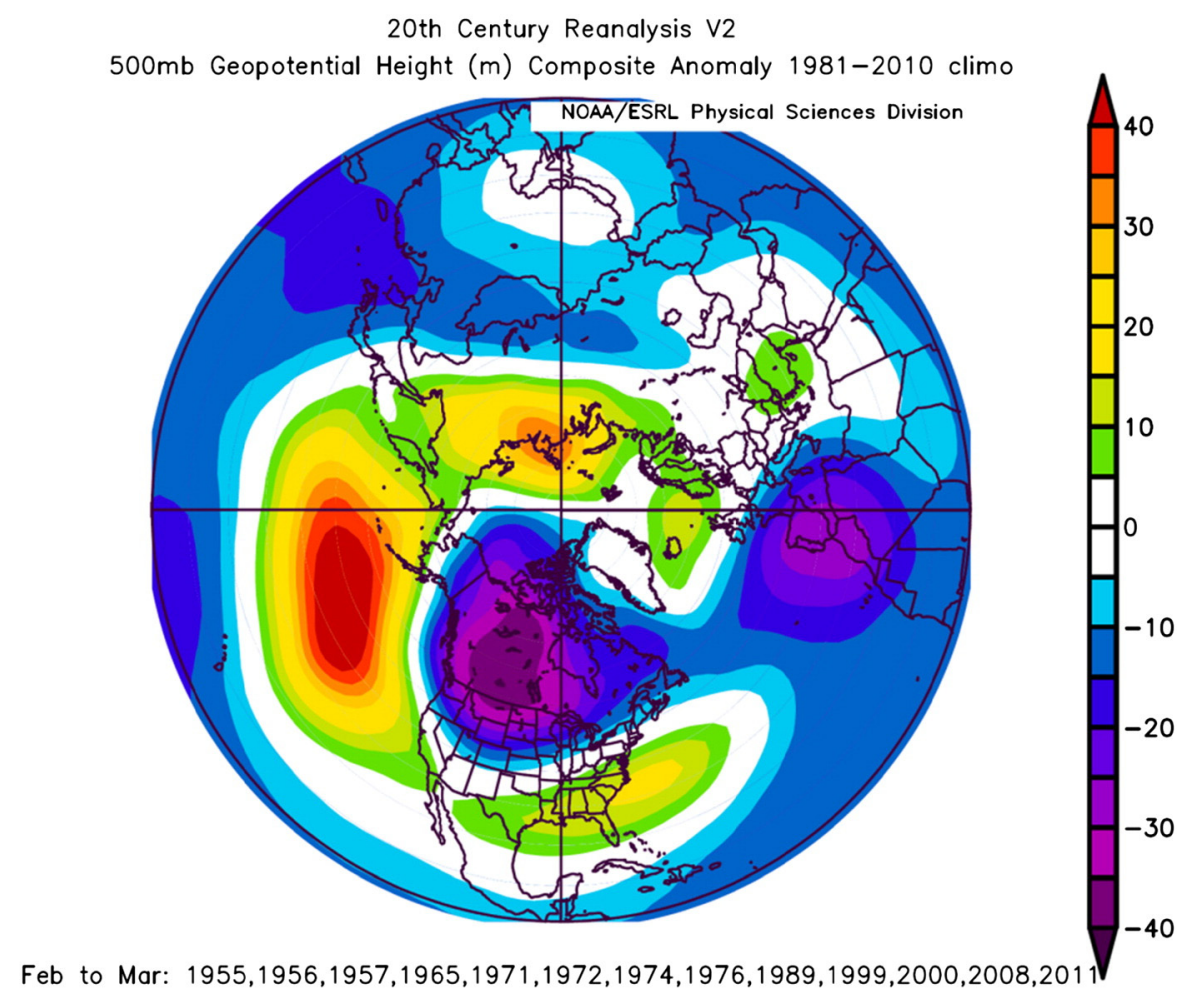

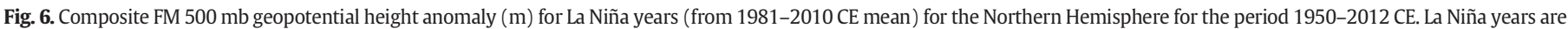

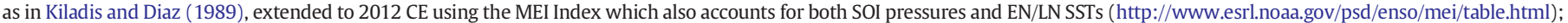

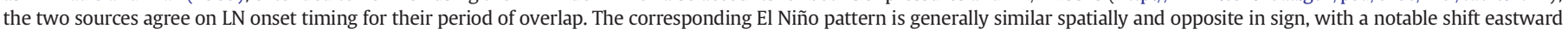
(towards Greenland) of the North American poleward pressure anomaly.

peaking somewhere within the first year and one-half after the event, followed by a gradual recovery over the subsequent years as the perturbation to the incoming energy flux declines and the mean planetary energy balance returns to its pre-eruption state. Using these simple energy balance considerations, one could describe the effects of volcanic forcing as a "throttling down" of the Earth's heat engine during the first couple years after an eruption until the stratospheric aerosols settle, and then the "throttling back up" of that engine as the system recovers towards its pre-eruption energy equilibrium. Interestingly, the dynamical response to these variations in the global energy balance could be asymmetric in the tropical Pacific. As the incoming heat from the sun is reduced after a volcanic eruption, the zonal circulation over the Pacific basin (the Walker Circulation) is weakened, potentially raising the chance for a warm EN event to develop (cf. Adams et al., 2003). Nevertheless, the actual formation of such an event depends on the state of the system at the time of the onset of the forcing. If an EN event is just winding down, then a subsequent thrust towards another event will be weakened; equally, if a strong LN event is developing as the forcing hits, a complete reversal may be physically unlikely. Conversely, if a moderate EN is about to develop, the additional support from the collapsing trade winds might work to enhance the event (as might have been the case after Tambora and Krakatau). While there appears to be a real tendency towards EN conditions in the immediate aftermath of a large volcanic perturbation (Emile-Geay et al., 2008; cf. Adams et al., 2003; Li et al., 2013), it is conceivable that composites of these first years after an eruption might suffer in clarity somewhat from the immediate pre-history of the events, where the noise in the system needs to be overcome before a consistent signal can emerge.

Nevertheless, the volcanic forcing does act to reset the timing of the internal variability in the tropics. After about two years, as the system begins to regain its energy equilibrium, the newly absorbed energy enhances the convection in the western tropical Pacific; this systematically strengthens the trade winds, and after a couple years of the system developing EN-like tendencies the direction of the zonal system now reverses. Because the pre-history has been largely eliminated, a consistent response to the strengthening trade winds then emerges through a systematic LN pattern. In fact, the systematic nature of this synchronized response is so strong in the results presented herein that not a single event in Years 3-5 shows a significant spatial correspondence to an EN event in either of the volcanic eruption sets. Such a strong response requires an underlying process that dominates natural internal variability. Such a consistent rebound of the system after volcanic events was already pointed out in Adams et al. (2003), where the cold LN signal exhibits higher statistical significance over the initial EN warm signal (also cf. Wilson et al., 2010). The spatial structure with the highest significance in our results is found in Year 3 over Western North America, and using the analogy of the Earth heat engine, it could be suggested that it takes about two to three years to synchronize the internal variability in the climate system to a strong radiative forcing. After such a "resetting of the internal clock", the system devolves again towards its more chaotic nature over the subsequent two or three years. The spatial temperature distribution over Western North America appears to directly reflect this process.

Although we find this hypothesis cogent and consistent with the results presented, the fact that the previously proposed initial tendency towards a warm EN-like response doesn't emerge from our analysis as significantly as in Adams et al. (2003) could also potentially result from a more complex combination of factors. For example, the reconstructions shown here exclusively employ proxies in a region that is teleconnected to the tropical SSTs that define the El Niño-La Niña system. They therefore are dependent on the dynamical response to the evolution of this mode of internal climate variability. When looking at years with additional, and in fact specifically large, perturbations from volcanic aerosols, however, the local post-volcanic signal is likely not a purely dynamical imprint of the circulation, but rather also contains a direct radiative response that could affect tree-ring growth rates, 
Year 0

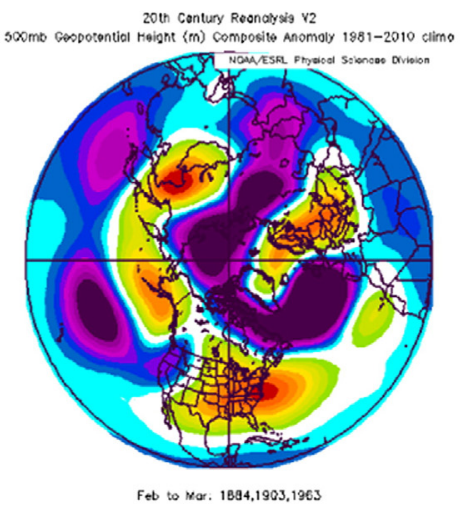

Year 4

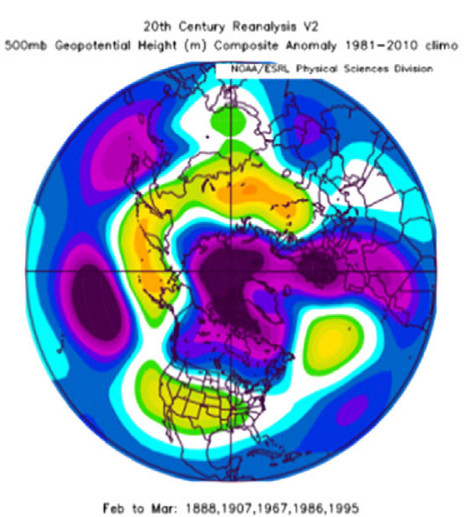

Year 1

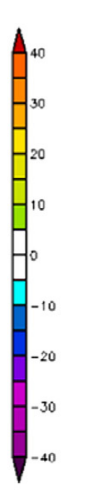

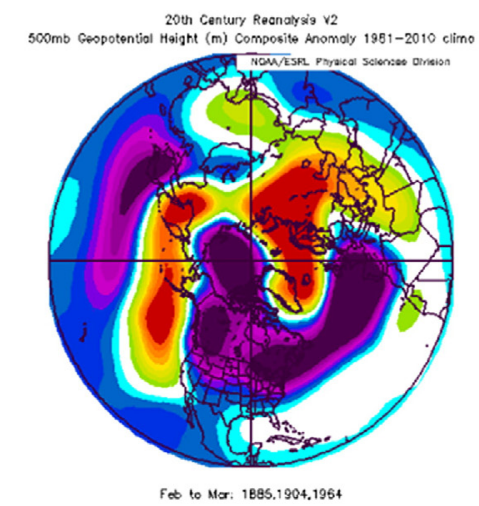

Year 5

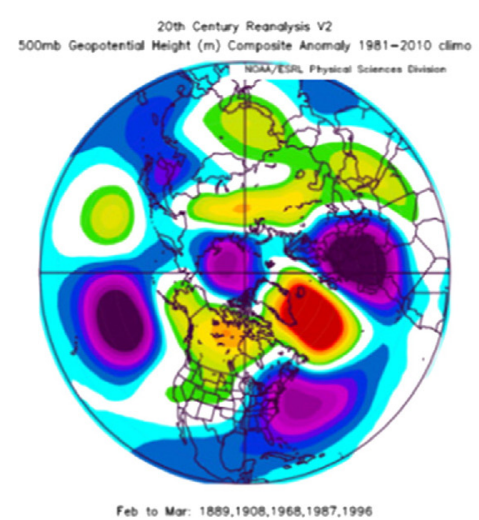

Year 2

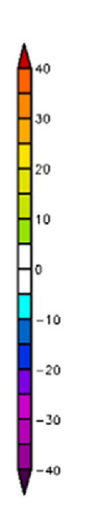

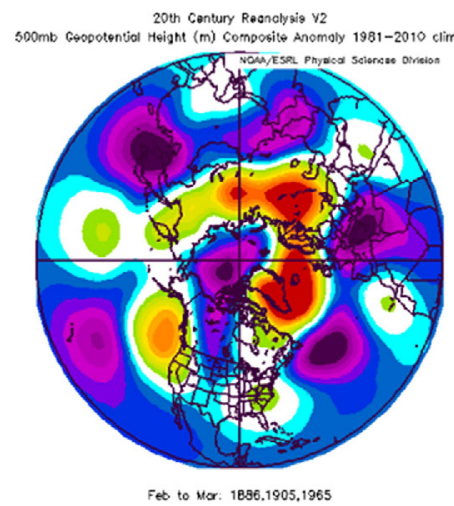

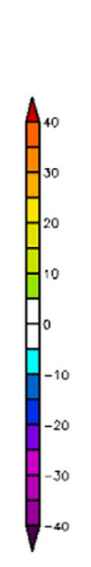

Year 6

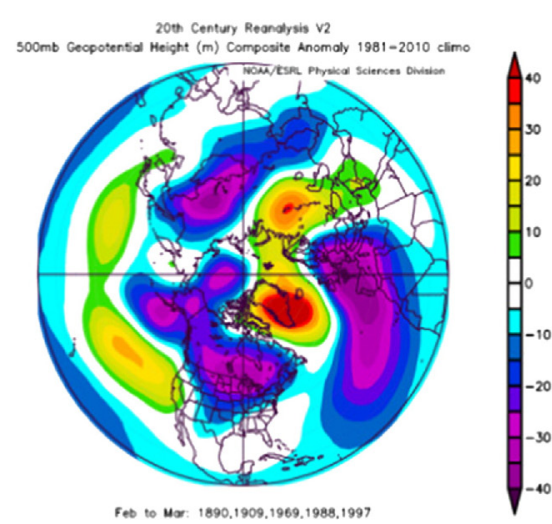

Year 3

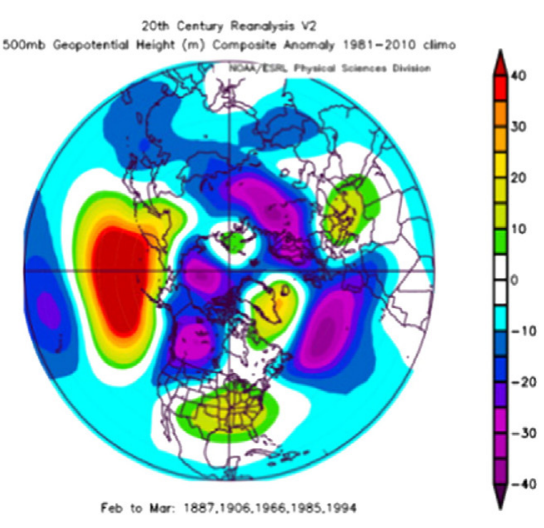

Year 7

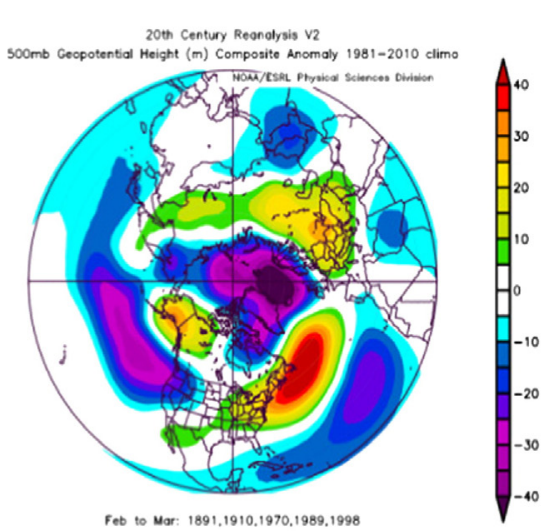

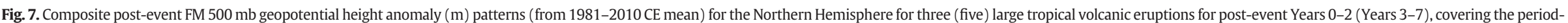

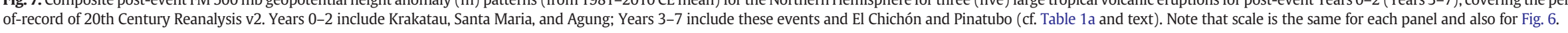


even if not a local temperature response (cf. D'Arrigo et al., 2009; Wilson et al., 2010). It might therefore be possible that the combined effects of the initial direct radiative perturbation together with a dynamical signal are mixed in the SEA composites and thus an extraction of a pure dynamical response might be somewhat obscured.

\subsection{Detection of post-volcanic spatial temperature response specific to North American West and Southwest}

As a final consideration, the relative strengths of the instrumental EOF patterns inherent in the reconstruction process (Fig. S5) are evaluated in terms of how these are expressed in the primary SEA composite patterns (Tables S1-2). A particularly strong contribution is found from EOF 3 (11\% of total variance), which is largely responsible for the distinct warming in the interior West and Southwest in Year 1 and the slight shift of the southern warm feature to the west and north in Years 3-5 in relation to the LN composite (Figs. 2, S5; Table S1) note that this latter feature occurs in the results from both eruption sets (Fig. 3). The EN and LN composites shown in Fig. 1(L) suggest that such a strong contribution could be distinctive to the postvolcanic response since the expression of EOF 3 in these composites is weak for EN and relatively weak compared to EOF 1 for LN (Figs. 1 (L), S5; Table S2). This suggestion is confirmed by the pattern correlation information in Table S1; in particular, the very high spatial correlations between EOF 3 and the primary SEA patterns for Years 3-5 are extraordinary, occurring less than $2 \%$ of the time in the random-event-year SEA null model ensemble (Table S1). This spatial structure also occurs at the annual time scale (11\% of total variance, WS12) and is robust to the data set used for analysis (Fritts, 1991, 13\% of total variance, cf. Fig. 4.5 therein). The relative strength of EOF 3 in Year 1 and Years 3-6 does not correspond in a systematic way to the post-event circulation anomalies (Fig. 7) and its persistence into years well after the event-year indicates that it is not explainable as a direct radiative effect. Further analysis of this regional structure is beyond the scope of this paper, and further research into the mechanisms of its post-event expression constitutes an important area for additional study identified in this work.

\subsection{Post-volcanic signal in dendroclimatic information: relationship of current work to recent evaluations}

In closing, we note recent discussion in the paleoclimatic literature that has evaluated the capability of tree ring information to capture post-volcanic responses in climate (Anchukaitis et al., 2012; Mann et al., 2012). We concur with Anchukaitis et al. (2012) that wellvalidated tree growth modeling in conjunction with both dendroecological and dendroclimatological empirical observations indicate no general problem of missing rings due to post-volcanic cooling, as postulated by Mann et al. (2012) based on the tree-growth simulations that they present. More specifically, we note the importance of spatial characteristics in the pattern of post-event responses highlighted by Anchukaitis et al. (2012). The primary purpose of this paper is the reconstruction and analysis of spatially-explicit mid-to-late winter temperature patterns in the temperate region of western North America that arise in response to large tropical volcanic eruptions: three additional lines of evidence lead to confidence in the spatial quality of our results and their use for subsequent analyses. First, the reconstruction methodology (cf. Data and methods above; Supplemental material, Section I; WS12 and its supplemental material) exhibits little general amplitude loss in simulation experiments (WS12 supplemental material, Section I), and while there may be potential for such loss in the case of extreme cold events (WS12 supplemental material, Section I), the general type of methodology used (principal components spatial regression) has been shown to retain good post-volcanic spatial pattern fidelity even in the face of amplitude loss (Jones et al., 2009, Fig. 5 and associated text). Second, the reconstructions clearly resolve known regional EN and LN winter temperature patterns, as noted (Fig. 1). Third, the pattern correlation analyses and significance results presented are robust both across the included EN and LN events and across the probabilistic ensemble of reconstruction members (Section 3.2; Figs. S7-8 and associated text). We therefore do not identify general concerns regarding either the incorporated proxy information or the reconstruction methodology employed that would motivate structural caution concerning our results and their interpretation for the purposes discussed herein.

\section{Acknowledgments}

The authors gratefully acknowledge the editor and two anonymous reviewers whose suggestions greatly enhanced the article. We also gratefully acknowledge Johannes Werner for perspective on the signal-to-noise analysis used to evaluate relative homogeneity of the regional post-volcanic spatial response. This study is supported in part by the Weather and Climate Impacts Assessment Science Program, NCAR (ERW and CMA). The National Center for Atmospheric Research is sponsored by the National Science Foundation. LDEO contribution 7824 .

\section{Appendix A. Supplementary data}

Online auxiliary material can be accessed at http://dx.doi.org/10. 1016/j.gloplacha.2014.08.005. The FM temperature reconstruction data will be available via NOAA Paleoclimatology, World Data Center for Paleoclimatology (http://www.ncdc.noaa.gov/dataaccess/paleoclimatology-data) upon publication.

\section{References}

Adams, J.B., Mann, M.E., Ammann, C.M., 2003. Proxy evidence for an El Niño-like response to volcanic forcing. Nature 426, 274-278.

Ammann, C.M., Naveau, P. 2003. Statistical analysis of tropical explosive volcanism occurrences over the last 6 centuries. Geophys. Res. Lett. 30 (5), 1210. http://dx.doi. org/10.1029/2002GL016388.

Ammann, C.M., Washington, W.M., Meehl, G.A., Buja, L., Teng. H., 2010. Climate engineering through artificial enhancement of natural forcings: magnitudes and implied consequences. J. Geophys. Res. 115, D22109. http://dx.doi.org/10.1029/2009JD12878.

Anchukaitis, K.J., Buckley, B.M., Cook, E.R., Cook, B.I., D'Arrigo, R.D., Ammann, C.M., 2010. Influence of volcanic eruptions on the climate of the Asian monsoon region. Geophys. Res. Lett. 37, L22703. http://dx.doi.org/10.1029/2010gl044843.

Anchukaitis, K.J., et al., 2012. Tree rings and volcanic cooling. Nat. Geosci. 5, 836-837. http://dx.doi.org/10.1038/ngeo1645.

Clement, A., Seager, R., Cane, M.A., Zebiak, S.E., 1996. An ocean dynamical thermostat. J. Clim. 9 (9), 2190-2196.

Coats, S., Smerdon, J.E., Cook, B.I., Seager, R., 2013. Stationarity of the tropical pacific teleconnection to North America in CMIP5/PMIP3 model simulations. Geophys. Res. Lett. 40. http://dx.doi.org/10.1002/grl.50938.

Compo, G.P., et al., 2011. The twentieth century reanalysis project. Q. J. R. Meteorol. Soc. $137,1-28$.

Cook, E.R., Krusic, P.J., Anchukaitis, K.J., Buckley, B.M., Nakatsuka, T., Sano, M., PAGES Asia2k Members, 2013. Tree-ring reconstructed summer temperature anomalies for temperate East Asia since 800 C.E. Clim. Dyn. 41, 2957-2972. http://dx.doi.org/10. 1007/s00382-012-1611-x

D'Arrigo, R., Wilson, R.E., Tudhope, A., 2009. The impact of volcanic forcing on tropical temperatures during the past four centuries. Nat. Geosci. 2, 51-56. http://dx.doi. org/10.1038/ngeo393.

Diaz, H.F., Hoerling, M.P., Eischeid, J.K., 2001. ENSO variability, teleconnections and climate change. Int. J. Climatol. 21, 1845-1862. http://dx.doi.org/10.1002/joc.631.

Driscoll, S., Bozzo, A., Gray, L., Robock, A., Stenchikov, G., 2012. Coupled model intercomparison project 5 (CMIP5) simulations of climate following volcanic eruptions. J. Geophys. Res. 117, D17105. http://dx.doi.org/10.1029/2012JD017607.

Emile-Geay, J., Seager, R., Cane, M.A., Cook, E.R., Haug, G.H., 2008. Volcanoes and ENSO over the past millennium. J. Clim. 21, 3134-3148.

Fischer, E.M., Luterbacher, J., Zorita, E., Tett, S.F.B., Casty, C., Wanner, H., 2007. European climate response to tropical volcanic eruptions over the last half millennium. Geophys. Res. Lett. 34, L05707. http://dx.doi.org/10.1029/2006GL027992.

Fritts, H.C., 1991. Reconstructing Large-scale Climatic Patterns from Tree-Ring Data: A Diagnostic Analysis. The University of Arizona Press, Tucson and London.

Hansen, J., Lacis, A., Ruedy, R., Sato, M., 1992. Potential climate impact of Mount Pinatubo eruption. Geophys. Res. Lett. 19, 215-218. http://dx.doi.org/10.1029/91GL02788.

Jones, P.D., and coauthors, 2009. High-resolution palaeoclimatology of the last millennium: A review of current status and future prospects. Holocene 19, 3-49.

Kiladis, G.N., Diaz, H.F., 1989. Global climatic anomalies associated with extremes in the southern oscillation. J. Clim. 2, 1069-1090. 
Landrum, L., Otto-Bliesner, B., Wahl, E.R., Conley, A., Lawrence, P., Rosenbloom, N., Teng, H., 2013. Last millennium climate and its variability in CCSM4. J. Clim. 26, 1085-1111. http://dx.doi.org/10.1175/JCLI-D-11-00326.1.

Li, J., Xie, S.-P., Cook, E.R., Morales, M.S., Christie, D.A., Johnson, N.C., Chen, F., D'Arrigo, R. Fowler, A.M., Gou, X., Fang, K., 2013. El Niño modulations over the past seven centuries. Nat. Clim. Chang. 3, 822-826. http://dx.doi.org/10.1038/nclimate1936.

Mann, M.E., Cane, M.A., Zebiak, S.E., Clement, A., 2005. Volcanic and solar forcing of the tropical Pacific over the past 1000 years. J. Clim. 18, 447-456.

Mann, M.E., Fuentes, J.D., Rutherford, S., 2012. Underestimation of volcanic cooling in tree-ring-based reconstructions of hemispheric temperatures. Nat. Geosci. 5, 202-205. http://dx.doi.org/10.1038/ngeo1394.

McGregor, S., Timmermann, A., 2011. The effect of explosive tropical volcanism on ENSO. J. Clim. 24. http://dx.doi.org/10.1175/2010JCLI3990.1.

Myhre, G., et al., 2013. Working Group I contribution to the IPCC Fifth Assessment Report (AR5), climate change 2013: the physical science basis chapter 8. Anthropogenic and Natural Radiative Forcing.

Pederson, G.T., Gray, S.T., Woodhouse, C.A., Betancourt, J.L., Fagre, D.B., Littell, J.S., Watson, E., Luckman, B.H., Graumlich, L.J., 2011. The Unusual Nature of Recent Snowpack
Declines in the North. Science 333, 332-335. http://dx.doi.org/10.1126/science. 1201570.

Robock, A., Taylor, K.E., Stenchikov, G.L., Liu, Y., 1995. GCM evaluation of a mechanism for El Niño triggering by the El Chichón ash cloud. Geophys. Res. Lett. 22, 2369-2372.

Smerdon, J.E., Kaplan, A., Zorita, E., González-Rouco, J.F., Evans, M.N., 2011. Spatial performance of four climate field reconstruction methods targeting the Common Era. Geophys. Res. Lett. 38, L11705.

Wahl, ER S Smerdon, J.E., 2012. Comparative performance of paleoclimate field and index reconstructions derived from climate proxies and noise-only predictors. Geophys. Res. Lett. 39, L06703. http://dx.doi.org/10.1029/2012GL051086.

Wegmann, M., Brönnimann, S., Bhend, J., Franke, J., Folini, D., Wild, M., Luterbacher, J., 2014. Volcanic influence on European summer precipitation through monsoons: possible cause for "years without summer". J. Clim. 27 (10), 3683-3691. http://dx. doi.org/10.1175/JCLI-D-13-00524.1.

Wilson, R.E, Cook, E.R., D'Arrigo, R, Riedwyl, N., Evans, M.N., Tudhope, A, Allan, R, 2010. Reconstructing ENSO: The Influence of Method, Proxy Data, Climate Forcing and Teleconnections. J. Quat. Sci. 25, 62-78. 